\title{
Making Sense Of Supply Disruption Risk Research: A Conceptual Framework Grounded In Enactment Theory
}

Scott C. Ellis

Jeff Shockley

Raymond M. Henry

Cleveland State University, r.henry22@csuohio.edu

Follow this and additional works at: https://engagedscholarship.csuohio.edu/bus_facpub

Part of the Business Administration, Management, and Operations Commons

How does access to this work benefit you? Let us know!

\section{Publisher's Statement}

This is the accepted version of the following article: Ellis, S. C., Shockley, J., Henry, R. M. (2011). Making Sense of Supple Disruption Risk Research: A Conceptual Framework Grounded In Enactment Theory. Journal of Supply Chain Management, 47(2), pp. 65-96, which has been published in final form at http://onlinelibrary.wiley.com/doi/10.1111/j.1745-493X.2011.03217.x/ full

Original Published Citation

Ellis, S. C., Shockley, J., Henry, R. M. (2011). Making Sense Of Supple Disruption Risk Research: A Conceptual Framework Grounded In Enactment Theory. Journal of Supply Chain Management, 47(2), pp. 65-96.

This Article is brought to you for free and open access by the Monte Ahuja College of Business at EngagedScholarship@CSU. It has been accepted for inclusion in Business Faculty Publications by an authorized administrator of EngagedScholarship@CSU. For more information, please contact library.es@csuohio.edu. 


\title{
MAKING SENSE OF SUPPLY DISRUPTION RISK RESEARCH: A CONCEPTUAL FRAMEWORK GROUNDED IN ENACTMENT THEORY
}

\author{
SCOTT C. ELLIS \\ University of Kentucky
}

JEFF SHOCKLEY

Radford University

\author{
RAYMOND M. HENRY \\ Cleveland State University
}

\begin{abstract}
The rich stream of supply disruption risk (SDR) literature incorporates several different theories and constructs across studies, but lacks a unifying decisionmaking framework. We review 79 SDR studies and advance a comprehensive framework, grounded in enactment theory, which integrates the disparate elements of SDR research and offers new insights into the SDR decisionmaking process. Enactment theory posits a three-stage, closed-loop process, consisting of enactment, selection and retention, through which individuals process and make sense of equivocal environments. We suggest that this sense-making process also underlies SDR decision-making, and provides the theoretical underpinnings for the environmental, organizational and individual factors that affect the formation of buyers' perceptions of SDR and the actions they take to mitigate such risks. In accordance with our conceptual framework, we develop seven propositions that advance the social and psychological factors that drive the idiosyncratic nature of SDR decisionmaking.
\end{abstract}

Keywords: risk/risk assessment; behavioral supply management; theory building.

\section{INTRODUCTION}

In 2000, a Philips NV semiconductor fabrication plant in Albuquerque, New Mexico was severely damaged by fire caused by a lightning strike (Lee 2004; Sheffi and Rice 2005). At the same time, the two major customers of this plant - Nokia Corp. and Ericsson LM - were launching a new generation of cell phones (Sheffi and Rice 2005). Nokia developed alternate sources of supply and worked with Philips to develop production capability in other chip fabrication centers around the world. Ericsson adopted a different strategy of buffering with inventory to "ride out" the perceived short-term loss in capacity (Schmitt 2008). During the period of the disruption, which extended far longer than Ericsson originally thought, Nokia increased market share while Ericsson suffered significant losses and was ultimately forced to exit select cell phone markets.

Supply disruptions can significantly reduce operational performance, profitability and shareholder value over the long term (Hendricks and Singhal 2003, 2005a, b; PricewaterhouseCoopers 2008). Moreover, supply chain managers expect that their vulnerability to supply disruptions will only increase in coming years (Juttner 2005). The operational and strategic implications of effective supply disruption risk (SDR) management have motivated scholars to explore a range of issues including the types of supply disruptions, assessment models and risk mitigation strategies. However, consistent with the views of Blackhurst, Craighead, Elkins and Handfield (2005), our review of 79 scholarly publications suggests that extant supply risk management research is highly 
fragmented. In particular, our findings indicate that the SDR stream of research incorporates several theories and constructs across disparate studies, but lacks a unifying framework. Further, the psychological and social theoretical underpinnings of SDR are in their incipient stages of development. As such, per the vignette above, it remains unclear why firms that are seemingly faced with the same nominal SDRs act in such different ways.

We address this gap in extant literature by applying Karl Weick's $(1969,1995,2001)$ enactment theory to the study of the SDR decision-making process. Central to enactment theory is sense-making - a closed-loop, socio-psychological process that describes how individuals resolve equivocality. As conceived by Weick (1969), the sense-making process is predicated on the notion that an individual's actions enable enhanced understanding of the environment, which in turn, influences future actions. Guided by enactment theory, we develop an integrative framework in which SDR decision-making is conceptualized as a specialized case of the sense-making process. Accordingly, we suggest that organizational buyers use the sense-making process to cope with equivocality that stems from the supply environment. Through our framework and related propositions, we advance substantive theory that explains how attributes of the (supply) environment, organization (i.e., firm) and individual (i.e., buyer) affect SDR decision-making and its efficacy.

Our research contributes to the body of SDR research in three important ways. First, our application of enactment theory facilitates the integration of disparate studies of SDR into a cohesive conceptual framework. Accordingly, we offer a comprehensive view of SDR decision-making that is grounded in phenomenological studies of SDR and supported by rationale culled from enactment theory. Second, our conceptual framework supports the notion that the perception of risk, rather than actual risk, influences the SDR decision-making process. As such, we advance a theoretical rationale that accounts for differences in objective versus perceptual views and explains why perceptions and mitigation actions vary across individuals faced with the same nominal risk. Third, our study builds on seminal models of risky decision-making (e.g., Sitkin and Pablo 1992; Yates and Stone 1992) by suggesting that equivocality affects how individuals process SDR decisions. Further, our substantive theory provides novel insights into the social and psychological theoretical mechanisms that underlie the formation of risk perceptions and adoption of specific risk mitigation tactics.

The remainder of this paper proceeds as follows. In the following two sections, we present a review of the SDR literature and describe enactment theory, respectively. Subsequently, we propose a conceptual framework that integrates key environmental, organizational and individual factors that affect the SDR decision-making pro- cess and draw from enactment theory to advance propositions that support our framework. In the final section, we discuss the theoretical and practical implications of our study.

\section{REVIEW OF SDR LITERATURE}

While the focus of our literature review is SDR, we recognize that the study of risk permeates the boundaries of several fields of academic research. Given the breadth of extant SDR research, we used two rules to constrain our review. First, we limited our review to articles that were published within peer-reviewed academic journals. Second, we constrained our review to those articles in which supply risk and/or disruption is the primary consideration. As such, we omit related streams of research, such as those addressing supply chain agility (e.g., Braunscheidel and Suresh 2009) and opportunism (e.g., Hallikas, Puumulainen, Vesterinen and Virolainen 2005), from our review. Application of these heuristics resulted in the identification of 79 SDR articles. In Table 1 , we briefly describe the risk elements, referenced theories, methodology, research focus and conclusions advanced within each of these articles.

\section{Theoretical Perspectives}

Organizational perspectives, such as transaction cost economics (TCE) and resource dependence (RD) theories, as well as real options approaches have played a central role in studies of SDR. Whereas TCE logic lends conceptual support for the links between SDR and (i) uncertainty and (ii) asset specificity, RD theory suggests that SDR is a function of dependence. Accordingly, previous research has used these organizational theories to examine the effects of supply base complexity, market thinness, technological dynamism, supply uncertainty, product customization, product importance and inventory buffering strategies on supply risk (Choi and Krause 2006; Wagner and Bode 2006; Khan, Christopher and Burnes 2008; Kull and Closs 2008; Ellis, Henry and Shockley 2010). Alternately, real options theory links postponement and SDR mitigation, suggesting that delayed investment reduces uncertainty by permitting more informed decision-making. Using this approach, Cucchiela and Gastaldi (2006) explain how defer, stage, explore, lease, outsource and other options may be used to mitigate risks stemming from internal and external sources of uncertainty. In the same vein, Hult, Craighead and Ketchen (2010) find that the use of deferral options, under conditions of high uncertainty, is positively related to supply chain project return on investment.

A burgeoning stream of SDR research has incorporated a behavioral perspective, which advances a perceptual view of risk and considers the psychological and social factors that affect the formation of risk perceptions. Such emphasis on risk perceptions stems from (i) the 


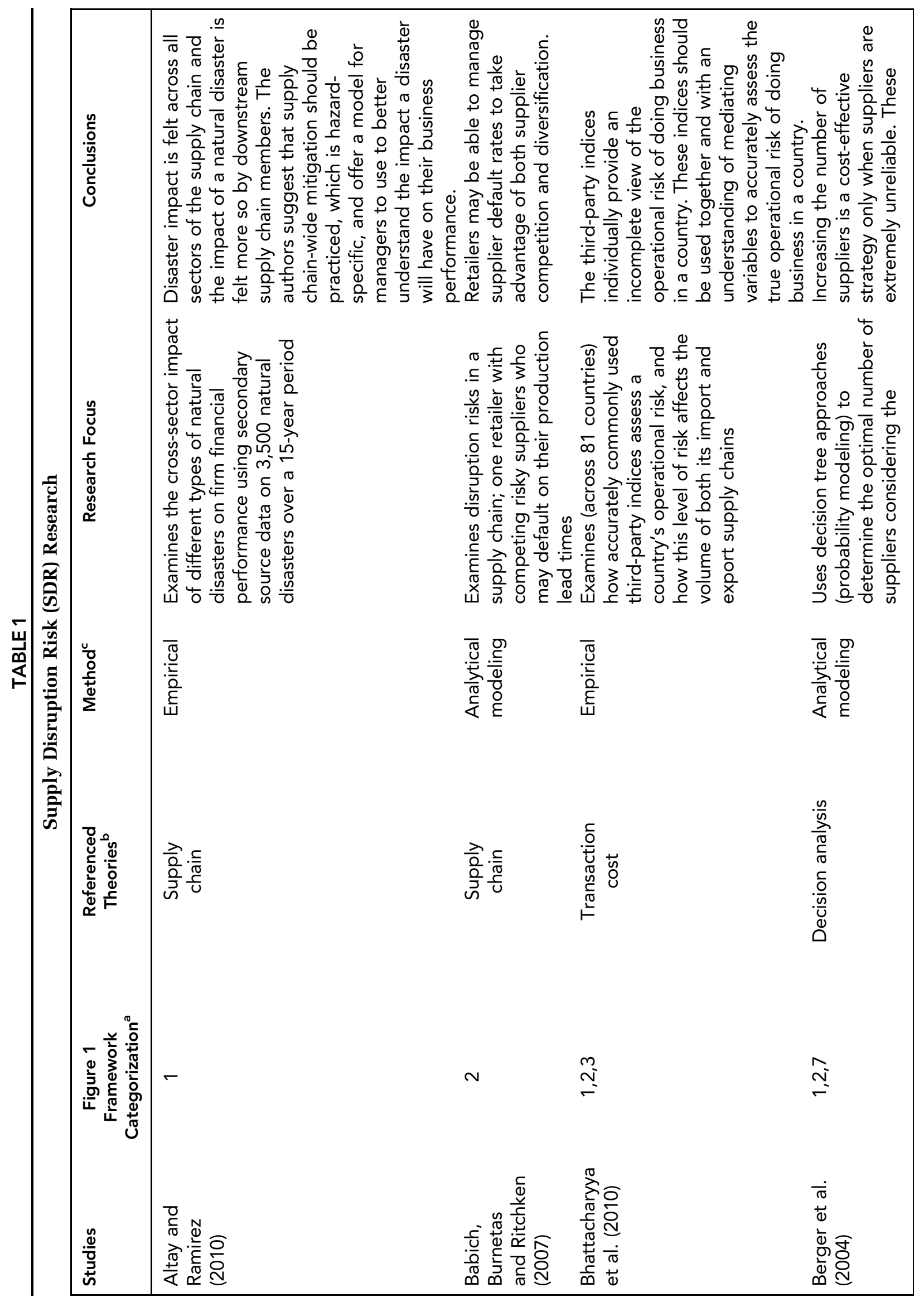




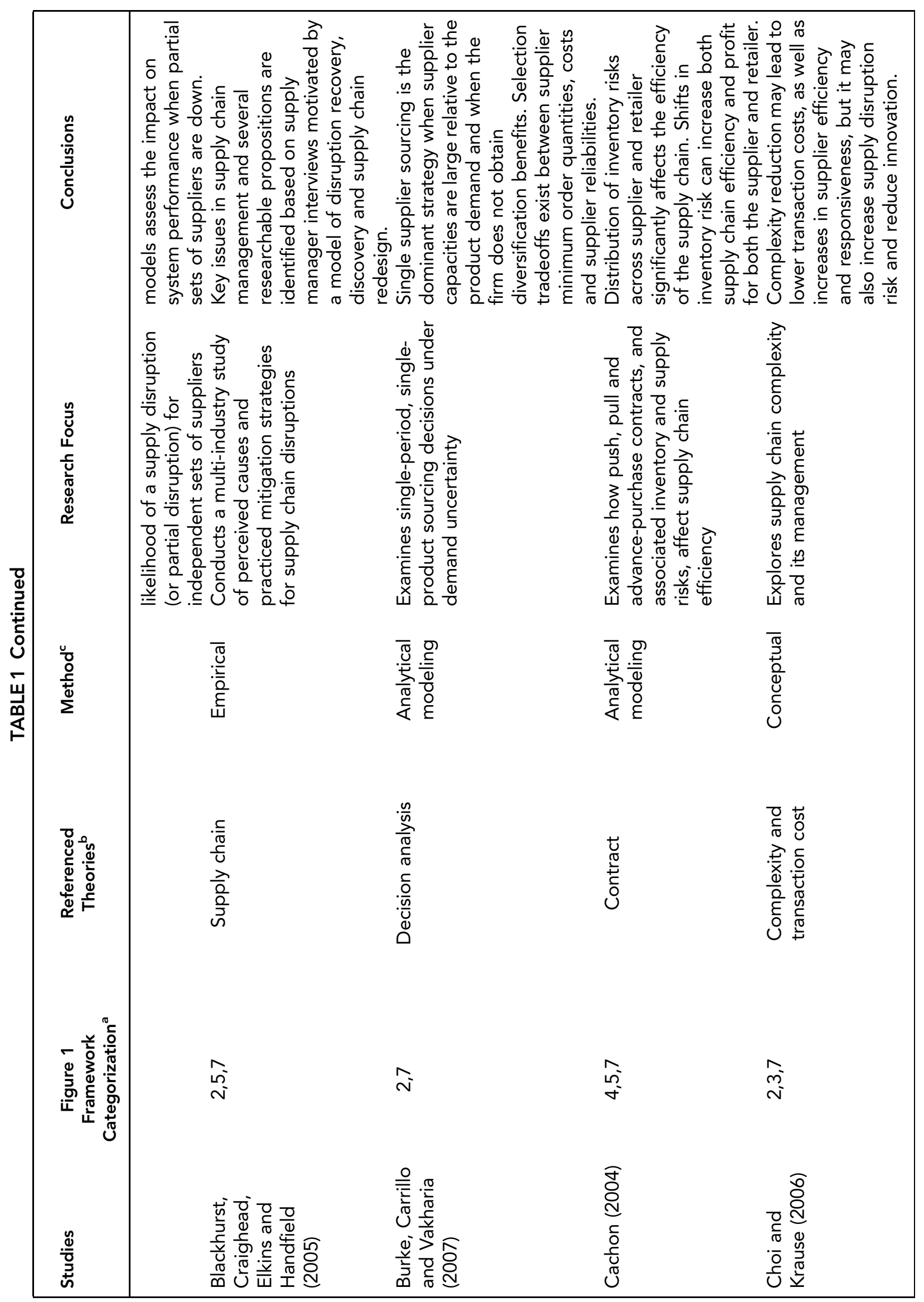




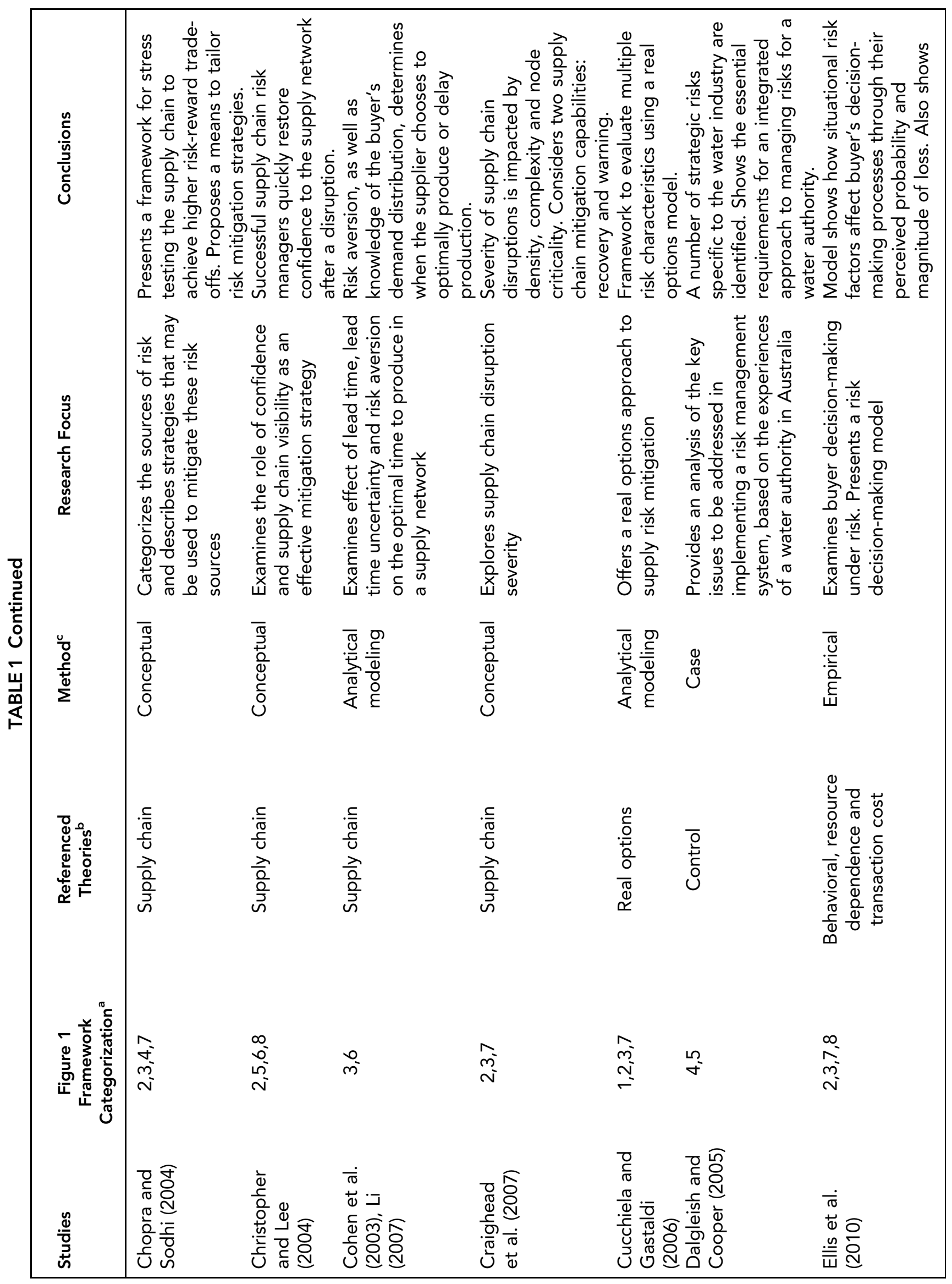




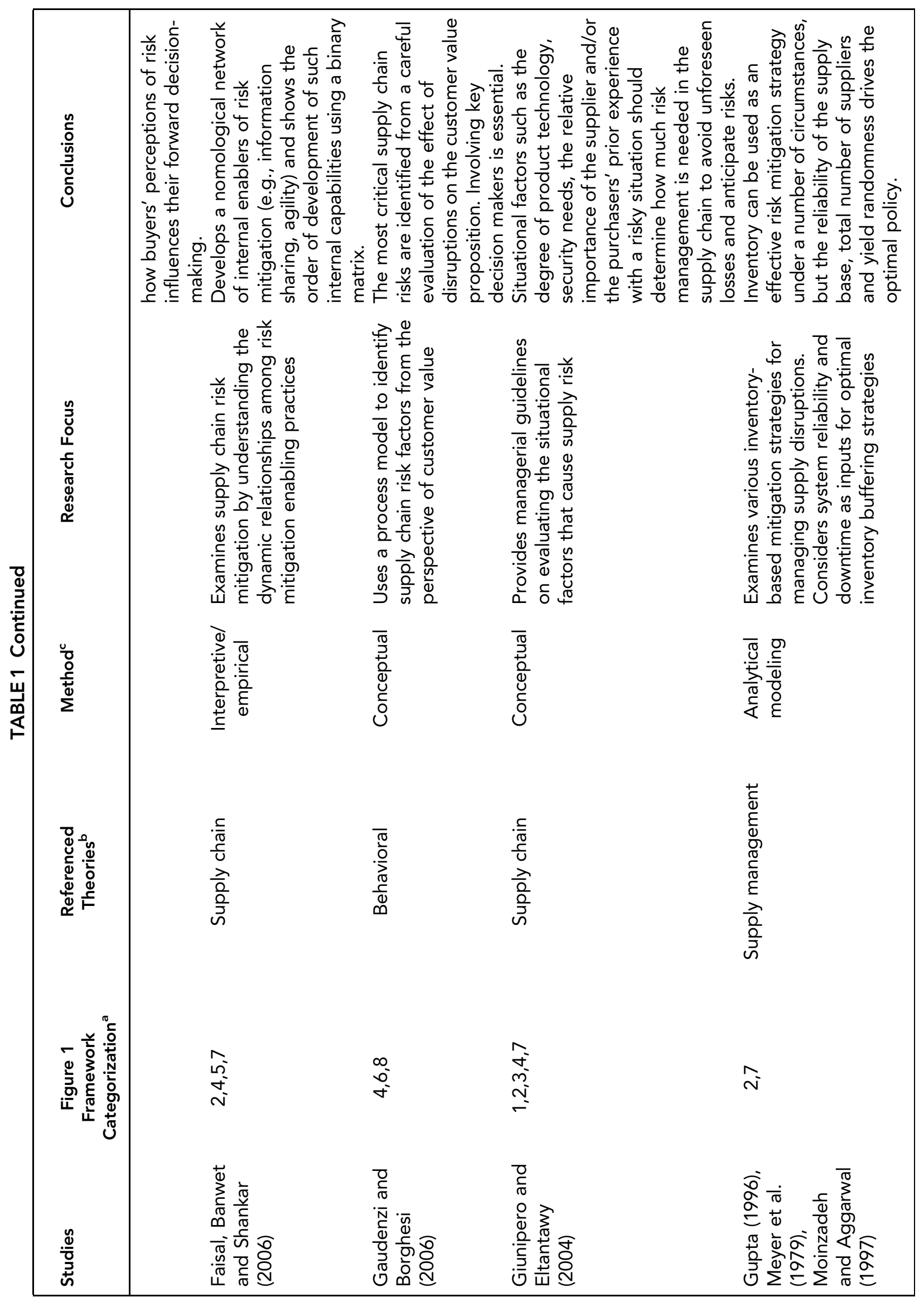




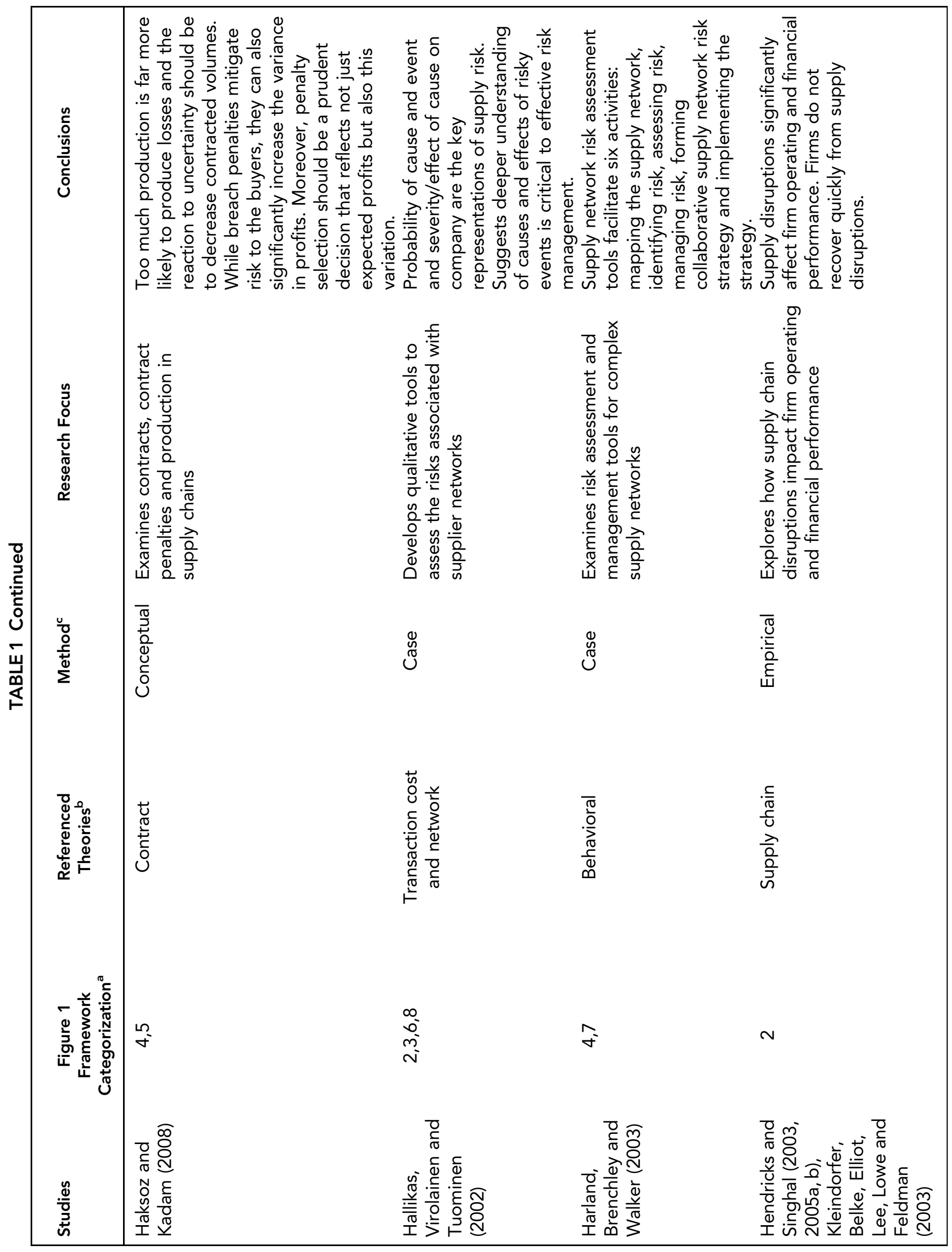









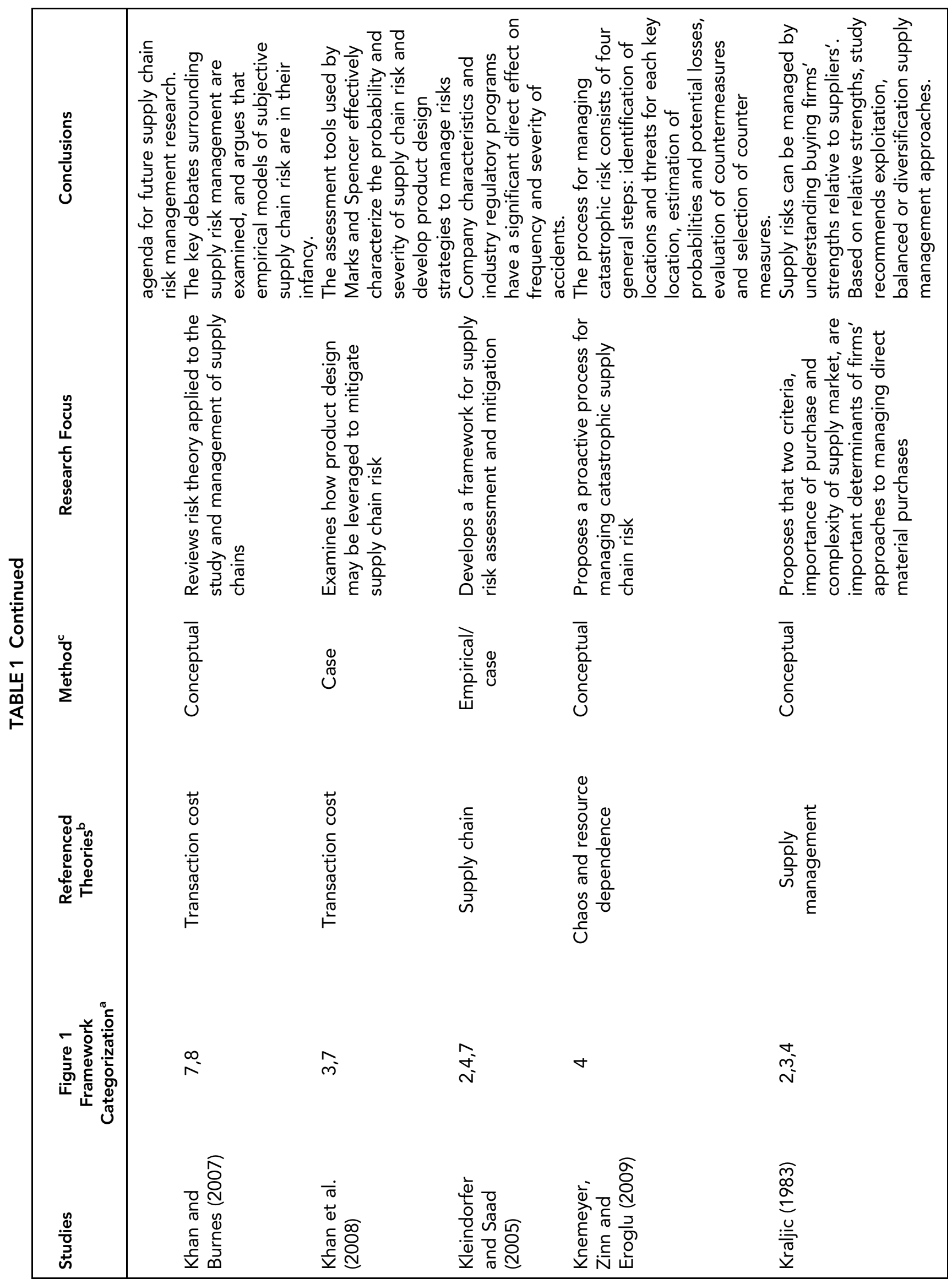




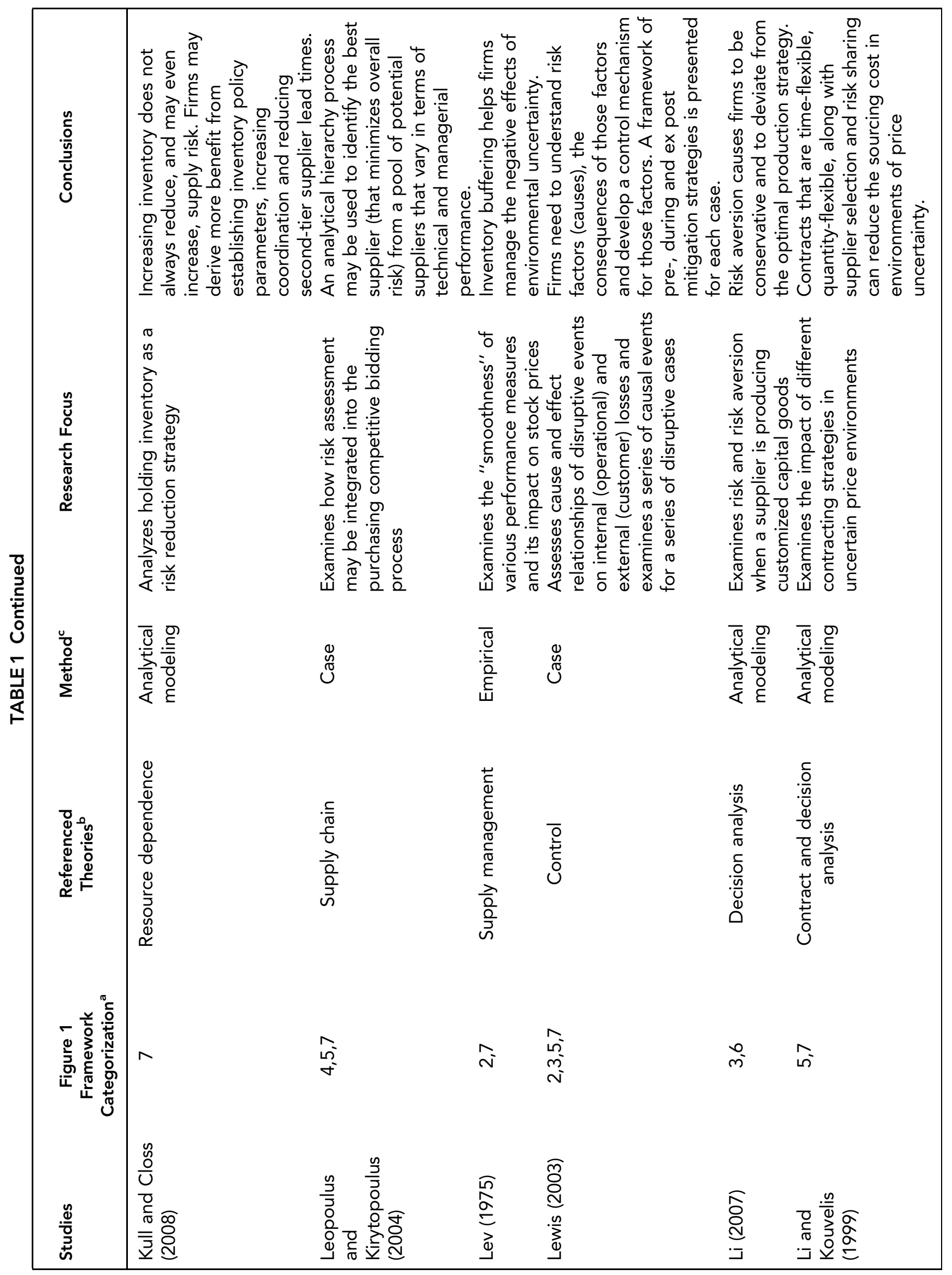




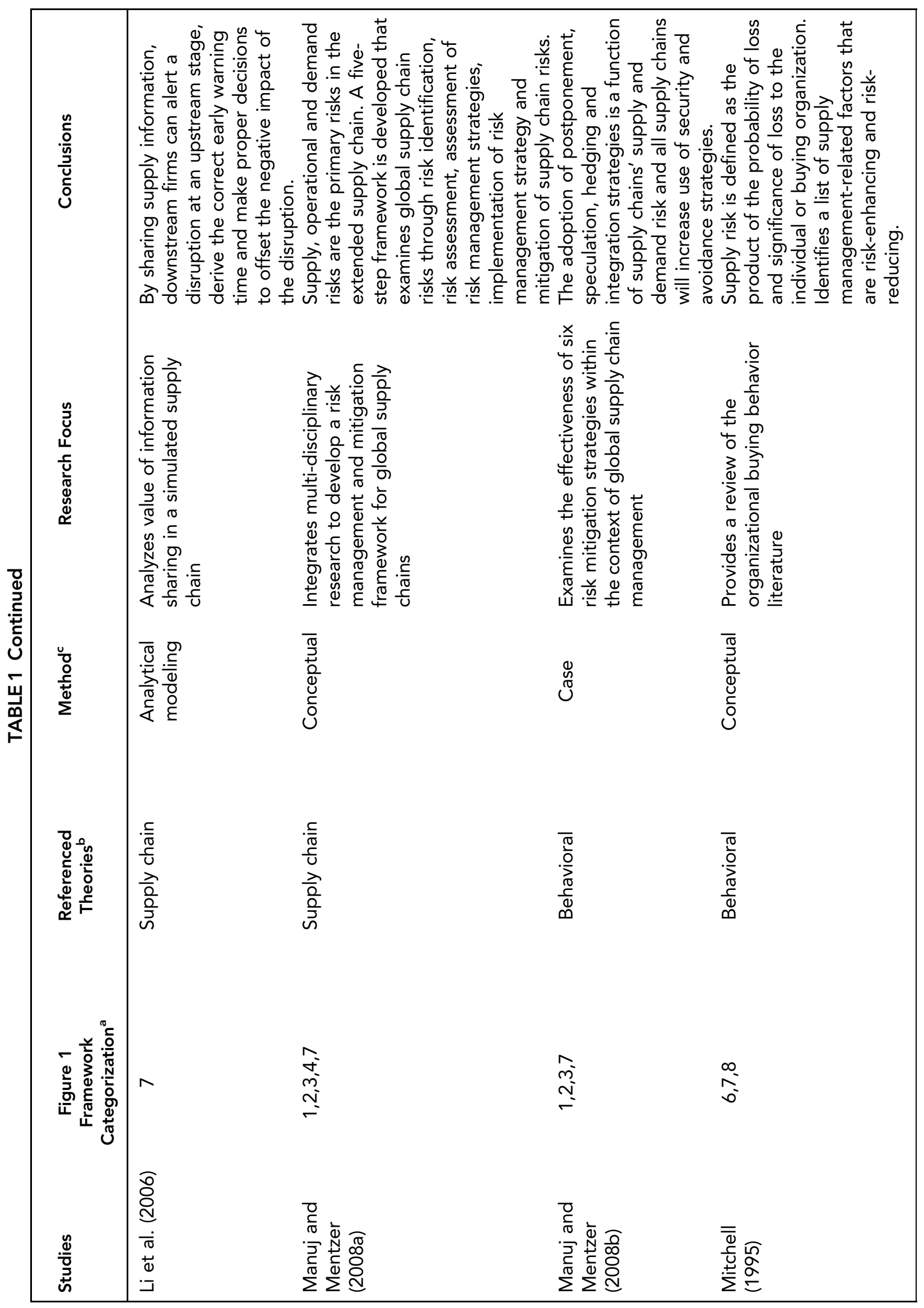




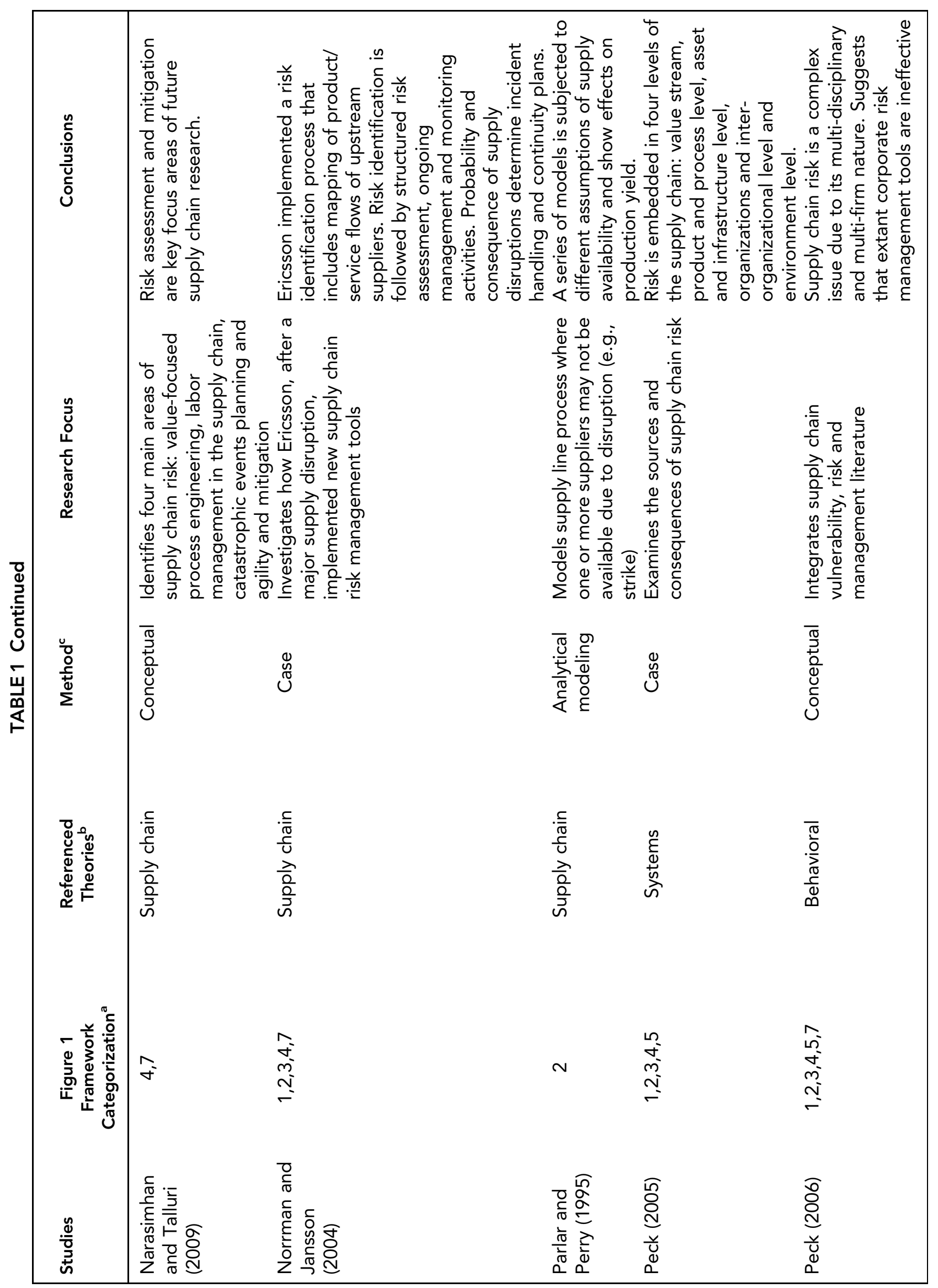




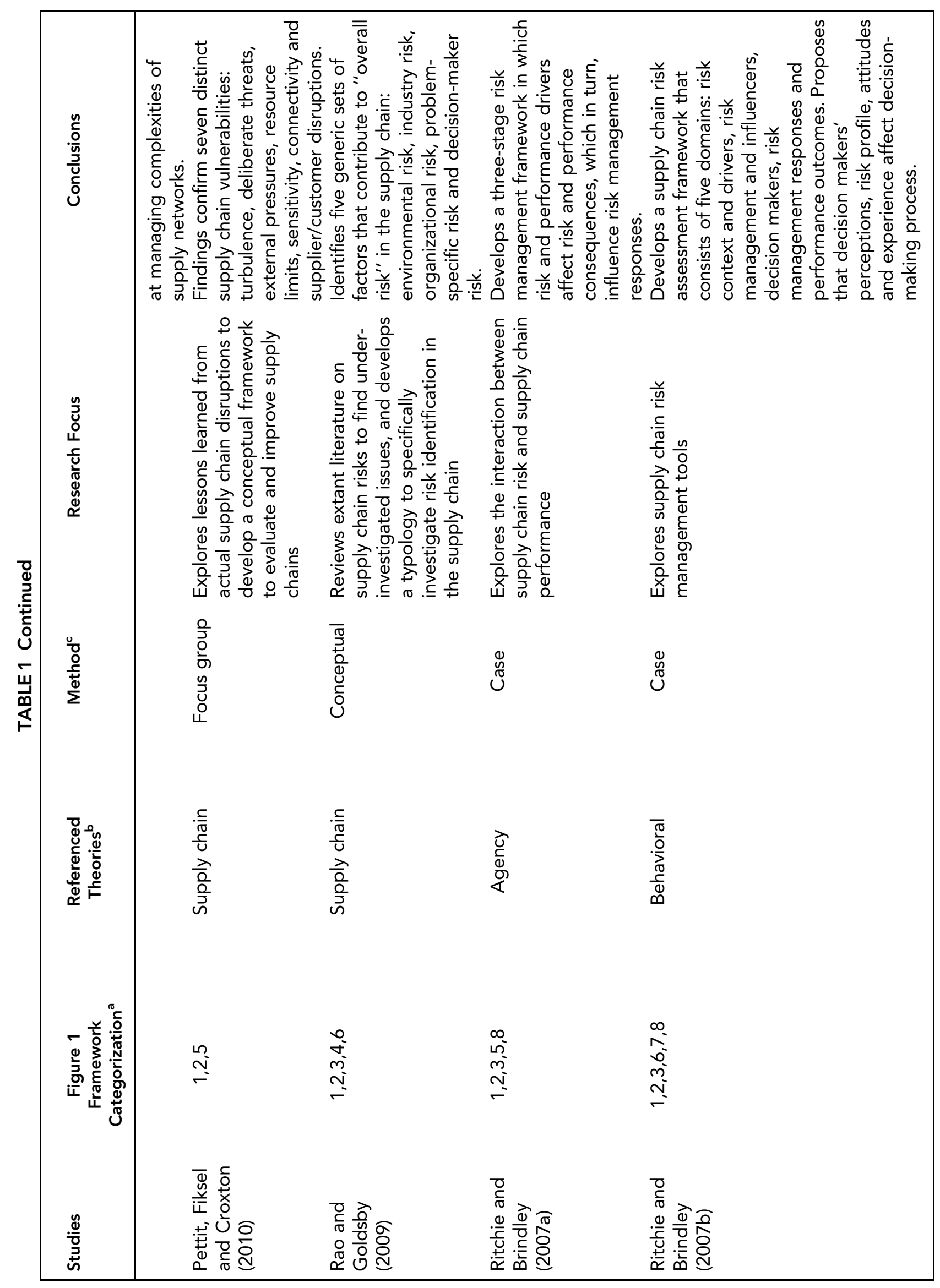




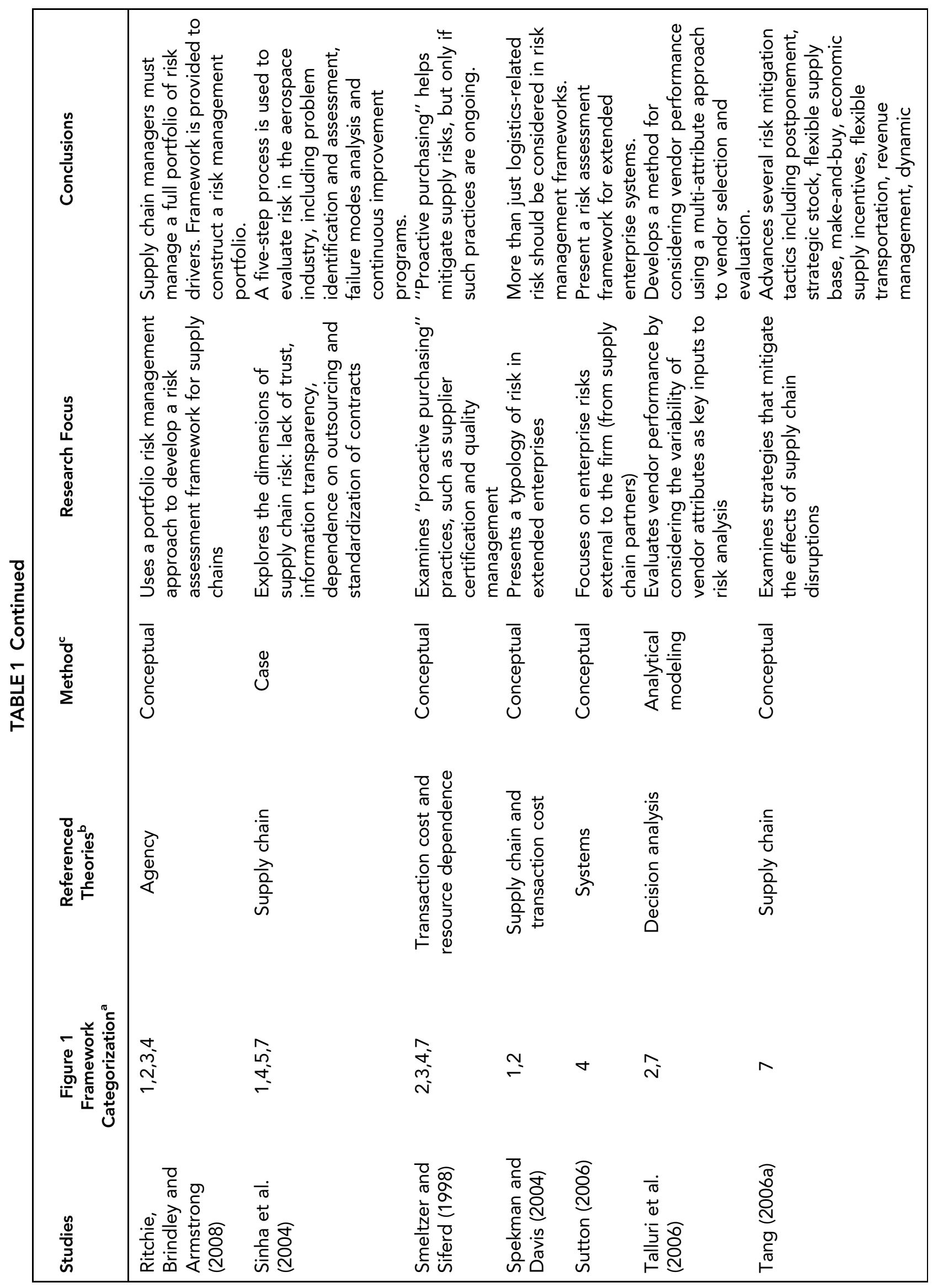




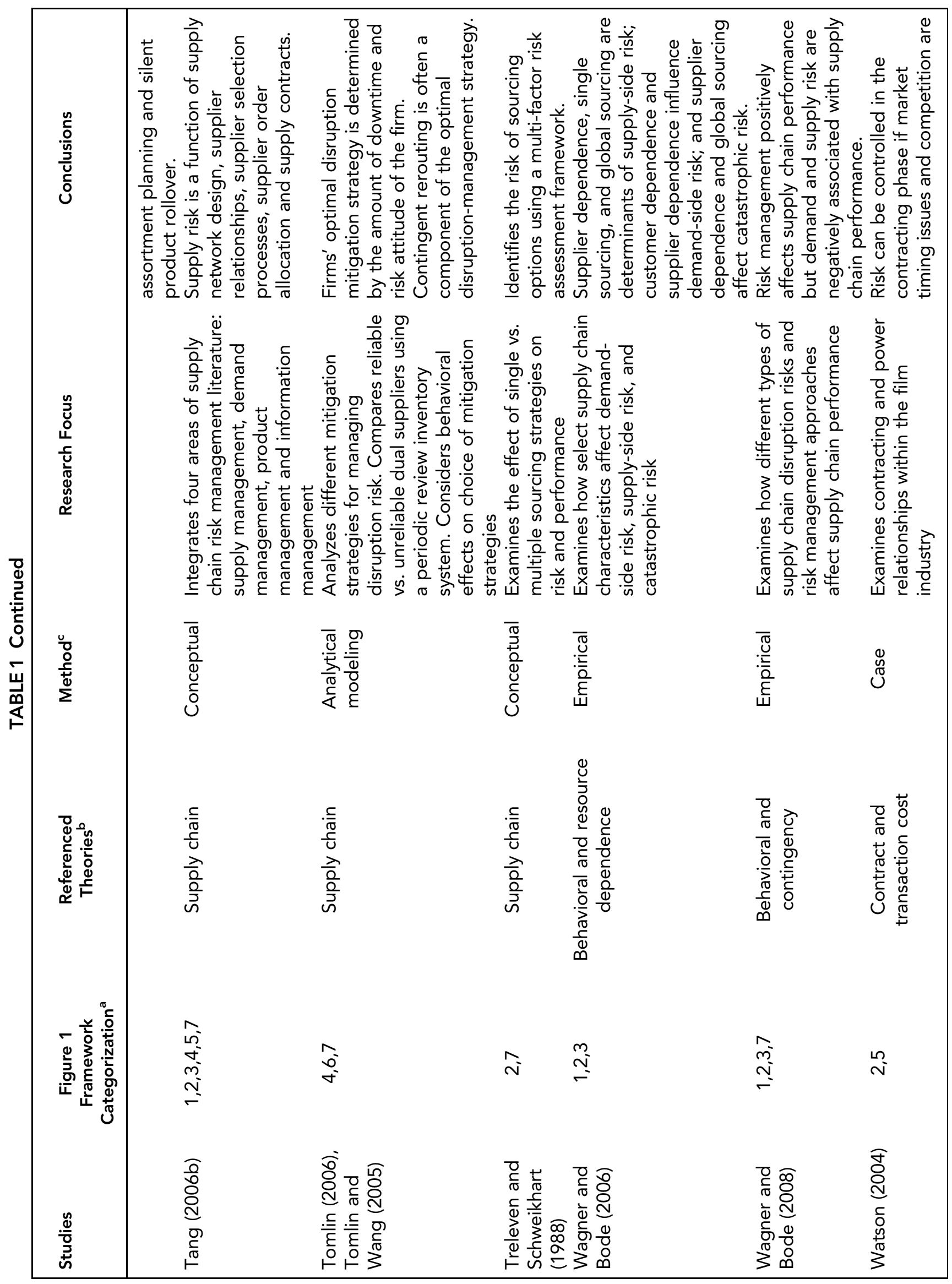




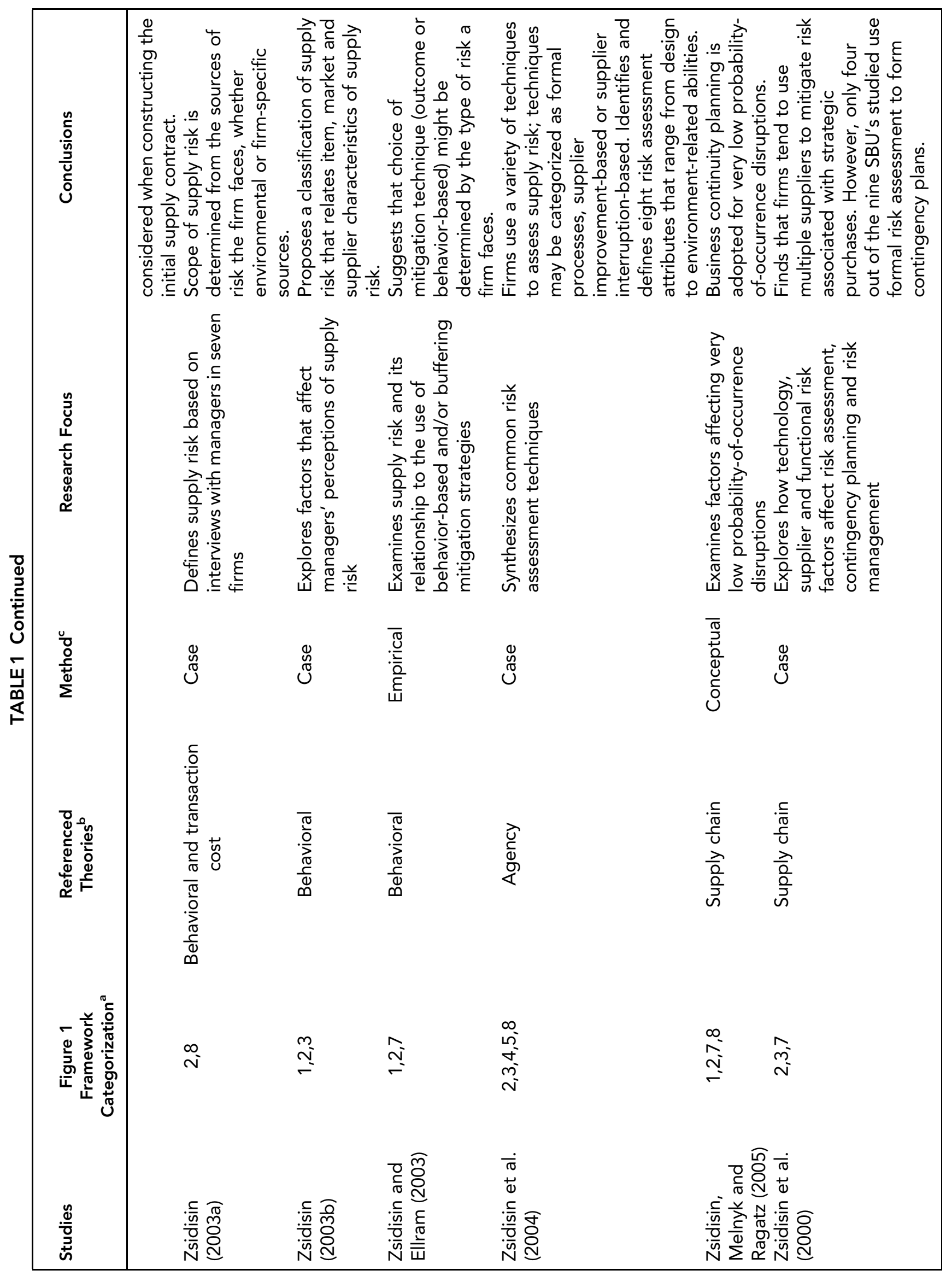




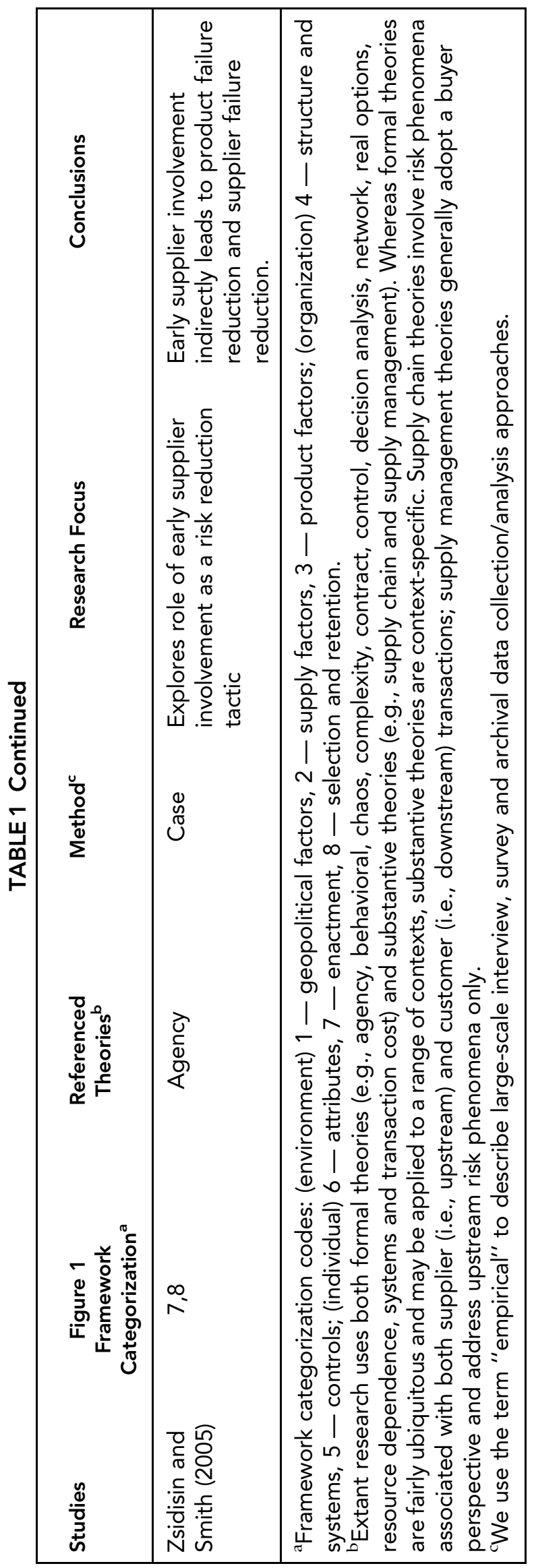

notion that perceptions of risk play a formative role within an individual's cognitive decision-making process (Yates and Stone 1992) and (ii) findings that managers' assessments of risk are often imprecise and different from those predicated on traditional decision theory (March and Shapira 1987). Accordingly, behavioral studies conceptualize SDR in terms of perceived probability and magnitude of loss and examine factors that influence overall perceptions of SDR (Zsidisin 2003a). Using a behavioral approach, Mitchell (1995) proposes several individual-level factors, such as buyer demographics and personality, that affect organizational buyers' risk perceptions. In the same vein, Ellis et al. (2010) find that environmental factors affect perceptions of probability and magnitude of loss, which in turn influence views of overall SDR.

\section{Definitions}

The variety of theoretical perspectives has facilitated the development of SDR-related definitions that are both objective and behavioral in nature. For example, Hendricks and Singhal (2005b, p. 35) adopt an objective view and define a supply chain disruption as "an indicator of a firm's inability to match demand and supply"; the authors assert that supply disruptions may be due to many reasons ranging from poor forecasting and planning to part shortages and production problems. Similarly, Craighead, Blackhurst, Rungtusanatham and Handfield (2007, p. 132) postulate that supply chain complexity is positively related to disruption severity; in their study, supply disruptions are defined as "unforeseen events that interfere with the normal flow of materials and/or goods within the supply chain." Other studies incorporate behavioral elements into definitions of SDRrelated constructs. For example, Zsidisin (2003a, p. 222) defines supply risk as "the probability of an incident associated with inbound supply from individual supplier failures or the supply market occurring, in which its outcomes result in the inability of the purchasing firm to meet customer demand or cause threats to consumer life and safety." Ellis et al. (2010, p. 36) build on this work and define SDR as "an individual's perception of the total potential loss associated with the disruption of supply of a particular purchased item from a particular supplier."

\section{Constructs and Findings}

Several aspects of risk, including antecedents and consequences of risk as well as risk assessment frameworks, have been explored in prior research. In aggregate, the SDR literature suggests many supply market-, supply base-, supplier- and product-related antecedents of SDR. Whereas supply market antecedents include factors such as market thinness, entry barriers and capacity availability (Kraljic 1983), supply base antecedents include the number of suppliers, density of the supply network, differentiation of suppliers and interrelationships be- 
tween suppliers (Choi and Krause 2006; Craighead et al. 2007). Extant research further suggests that supplier attributes, such as supplier capabilities, performance and size (Mitchell 1995; Cohen, Ho, Ren and Terwiesch 2003; Zsidisin 2003a), and product characteristics, like level of customization and pace of technological change (Kraljic 1983; Giunipero and Eltantawy 2004; Ellis et al. 2010), influence SDR.

Several studies find a significant relationship between supply disruption and firm performance. In particular, results from empirical research indicate that supply disruptions are negatively related to buying firms' stock performance (Hendricks and Singhal 2003, 2005b; Hendricks, Singhal and Zhang 2009) and operational performance (Hendricks and Singhal 2005a). These studies have motivated a related stream of research that proposes risk assessment methodologies and tactics to mitigate SDR. Within this research stream, Kleindorfer and Saad (2005) develop a comprehensive, stepwise approach to identifying and mitigating risks. Similarly, Sheffi and Rice (2005) propose the use of vulnerability maps to aid in the identification and mitigation of supply risks. Several mitigation tactics, such as early supplier involvement (Zsidisin and Smith 2005), information sharing (Li, Lin, Wang and Yan 2006), buyer-supplier relationship management (Sinha, Whitman and Malzahn 2004), contingency planning (Tomlin and Wang 2005; Tomlin 2006), sourcing policy and philosophy (Treleven and Schweikhart 1988; Smeltzer and Siferd 1998; Zsidisin, Panelli and Upton 2000) and inventory policy (Meyer, Rothkopf and Smith 1979; Gupta 1996; Moinzadeh and Aggarwal 1997; Kull and Closs 2008), may reduce the likelihood and/or severity of supply disruption.

\section{Gaps and Trends}

Our review of the SDR literature leads us to draw three important conclusions. First, we find that risk drivers, consequences of risk, risk mitigation tactics and risk assessment represent important elements of a comprehensive model of SDR. However, these important components are not well integrated in existing research. Second, our review suggests the growing importance of incorporating organizational and individual factors into SDR research. However, this effort is only in its incipient stages; we find few empirical studies of SDR that draw on such variables to explain disruption risk phenomena. Third, our findings indicate a developing consensus that behavioral views are important to our understanding of SDR. However, extant SDR research provides limited insight into the social and psychological mechanisms that underlie SDR perceptions and the SDR decision-making process.

\section{ENACTMENT THEORY}

Enactment theory concerns the psychological and social processes through which individuals and organizations derive meaning, or "make sense," from their experiences (Weick 1969, 1995, 2001). Fundamental to this theory is sense-making - a closed-loop process comprised of enactment, selection and retention activities that enable individuals to resolve equivocality (Weick 1969). Equivocality denotes the extent to which multiple meanings are linked with situation and arises when (i) derived meanings are subject to infinite revision as events unfold and conflicting individual and social explanations are invoked and (ii) the relative superiority of a particular explanation remains ambiguous (Weick 2001, p. 10). With high levels of equivocality, the environment is unanalyzable and enactment becomes the primary means of understanding (Weick 2001).

\section{Sense-making Process}

Within the sense-making process, enactment represents the execution of actions that are guided by preconceptions but may not be fully understood by the actor (Weick 2001). Accordingly, enactment incorporates previous understanding and provides the raw material for subsequent clarification of understanding. Selection refers to the interpretation process in which individuals attach meanings to actions by constructing plausible stories that explain current accounts of enactment (Weick 2001). In effect, an individual "selects" a contextually rational explanation, from those available, that best utilizes past wisdom and experiences. Through the selection process, past experiences constrain and preconceptions influence, current understanding. As such, the selection process accounts for the extent to which the perceived, enacted environment matches an objective reality and is critical to the accurate judgment of risk.

Through enactment and selection, salient entities are identified and cause-effect relationships are developed; in the subsequent retention process, these entities and their cause-effect relationships are stored within cognitive cause maps. The resulting cognitive cause map exists within the mind of the individual and represents (i) past wisdom, that is, "knowledge of what one thinks" (Weick 2001, p. 189), (ii) the criteria that influences what is noticed versus ignored, and how one will act (Weick 1969) and (iii) the enacted environment (Weick 2001). Through closed-loop process feedback, retained wisdom may constrain future actions and/or influence how future actions are interpreted (Weick 2001). As such, through the enactment-selection-retention process, action is informed and the capacity for judgment is developed.

Organizations augment the sense-making process through aggregating cognitive mechanisms such as group mind and collective cause maps. Group mind refers to the cognitive interdependence that forms among individuals that maintain close relationships; through such 
relationships, individuals "enact a single transactive memory system, complete with differentiated responsibility for remembering different portions of common experience" (Weick 2001, p. 260). Commonalities across individuals' cognitive cause maps form the basis for organizational values and goals that guide enactment and selection activities (Weber and Glynn 2006). As such, collective cause maps, supported by organizational structure, systems and controls, facilitate reductions in equivocality by constraining the number of acceptable meanings that may be attached to an event.

\section{Core Principles}

Enactment theory employs two salient principles, involving rationality and interaction, which facilitate the development of our conceptual framework. The first principle holds that individuals behave with constrained rationality that is retrospective in nature. Constrained rationality implies that individuals "act rationally within the limits of the [cognitive cause] maps they build" (Weick 2001, p. 322). Simplifying procedures applied to cognitive cause maps suggest that individuals pursue reasonable rather than economically optimal strategies to cope with equivocality. The retrospective nature of rationality focuses on justifying enactment rather than planning future action; in this post hoc view, rational behavior is situation-dependent and involves justification of enactment that facilitates legitimacy with impor- tant members of the social unit (i.e., leaders of the organization).

A second underlying principle of enactment theory suggests that interaction, and associated committed action, represent the fundamental elements of social organization. Interaction refers to the action-response dyad that interlocks individuals' behaviors and provides the context for committed action - action that is irrevocable, public and volitional and to which individuals become bound (Weick 2001, p. 17). Committed action gives rise to organization as individuals become dependent on those with whom they interact in order to achieve desired outcomes. Coordination results as individuals (i) adopt shared goals that justify committed actions and (ii) conduct actions heedfully while envisioning the joint actions of the organization (Weick 2001). Thus, the principles of rationality and interaction, coupled with the need to cope with equivocality, render the individual, organization and environment inextricably intertwined.

\section{SDR CONCEPTUAL FRAMEWORK}

Through the lens of enactment theory, we develop a conceptual framework that advances understanding of the SDR decision-making process. As shown in Figure 1, our framework integrates extant SDR research (see categorization references in Table 1 that link SDR studies with Figure 1) with constructs culled from organizational

FIGURE 1

Supply Disruption Risk (SDR) Conceptual Framework ${ }^{1,2}$

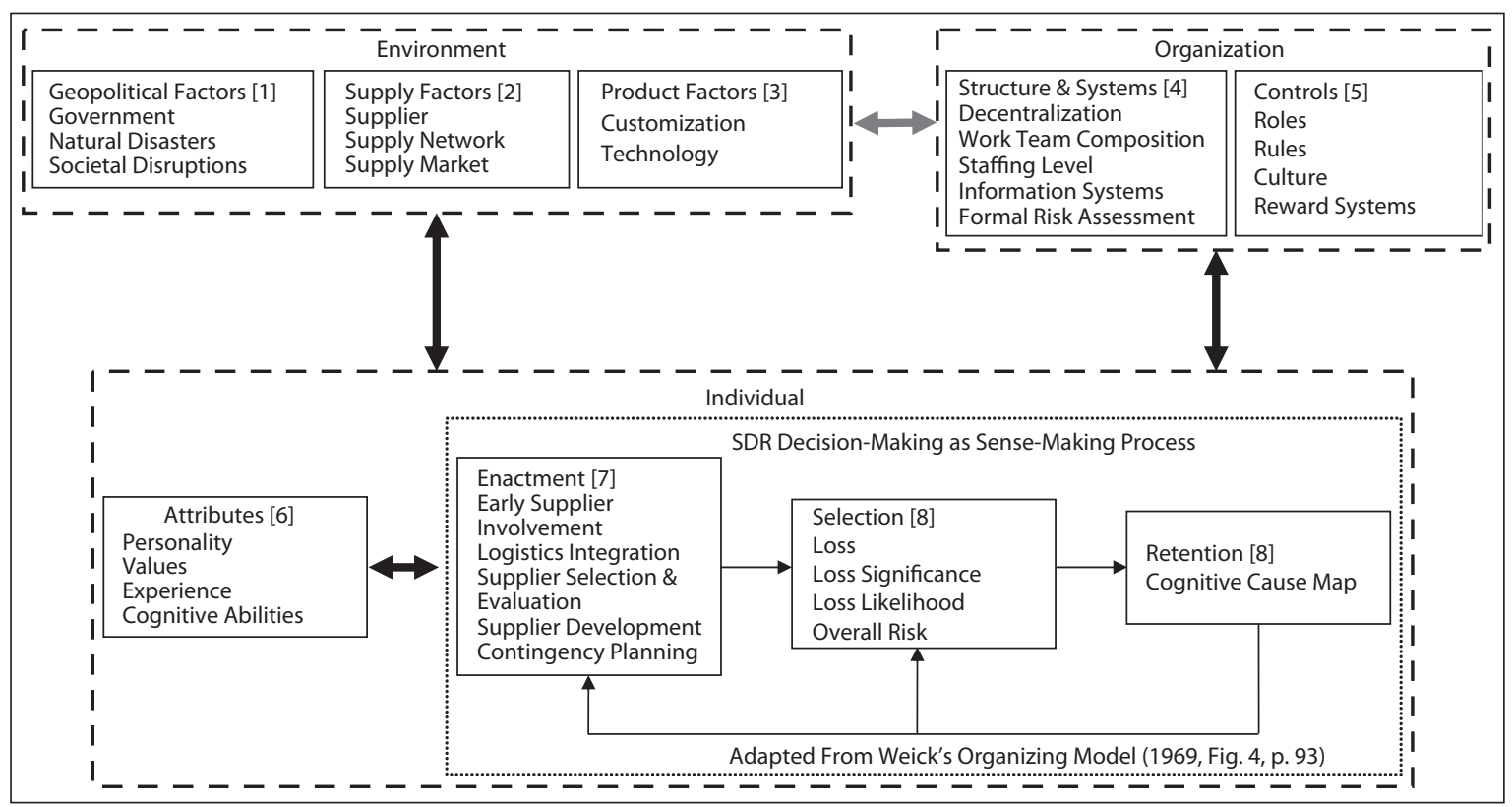

\footnotetext{
${ }^{1}$ The numbers in brackets serve as common references that link sets of factors to the SDR studies presented in Table 1.

${ }^{2}$ We set the color of the double-ended arrow that links environmental and organizational factors to gray to denote that this set of relationships is not germane to our theoretical development. While we acknowledge the existence of this relationship, the focus of this study is on how environmental, organizational and individual factors affect the sense-making process.
} 
and behavioral literature. We adopt three units of analysis - environment, organization and individual - to serve as the fundamental building blocks of our framework and use double-headed arrows to represent the interdependent nature of these units of analysis. The interdependence among individual, organization and environment is driven by three principles culled from enactment theory: (i) environments are enacted through individuals' actions, (ii) organizations, which represent individuals' social structures, interact with the environment through individuals' actions and (iii) through the sense-making process, organizations augment individuals' ability to understand the environment (Weick 2001). We conceptualize an "organization" as a firm and suggest that the "environment" consists of entities external to the firm that are not subject to direct control through ownership or fiat. The "individual" is a buyer of direct materials; buyers enact their environments through the adoption of risk mitigation actions and the meaning that is derived from these actions.

In the context of SDR decision-making, we draw from enactment theory to suggest that the socio-psychological sense-making process underlies the formation of buyers' SDR perceptions and decisions to mitigate such risks. At the individual level, we conceptualize the SDR decisionmaking process as a specialized case of sense-making in which judgments and evaluations of risk and adoption of risk mitigation tactics may be viewed as situation-specific enactment, selection and retention activities. We posit that equivocality, and its reduction, link environmental, organizational and individual factors to the SDR decision-making process. Whereas equivocality stems from the supply environment, buyers invoke the sense-making process to resolve such equivocality. In the course of sense-making, buyers enact risk mitigation strategies (i.e., enactment) and form judgments and overall appraisals of SDR (i.e., selection) which are retained to inform subsequent enactments (i.e., retention). Further, we posit that individual and organizational factors affect how equivocality is resolved and, subsequently, how SDR perceptions are formed and managed. Thus, the level of equivocality inherent in the supply environment, coupled with the organizational and individual factors that affect the equivocality resolution process, cause the SDR decision-making process to vary significantly across buyers and their firms.

\section{Environment}

Traditionally, the environment has been defined in terms of resources, complexity, interdependence and markets (Porac, Thomas and Baden-Fuller 1989; ScheidCook 1992). An important distinction lies in the contrast between "enacted environment" and "environment." Whereas the enacted environment refers to a mental model stored within the mind of an individual, the concept of environment is much broader in nature. The narrow scope of enacted environment is attributable to the notion that individuals, due to their bounded rationality, cannot attend to and interpret all possible environmental cues; through the sense-making process, an individual forms a mental model of the environment that is only a "partial representation of a larger transactional network" (Porac et al. 1989, p. 399). In contrast, the broader notion of environment extends beyond an individual mind and represents an objective reality that may not be fully known or accurately understood by an individual. Within our framework, we conceptualize the broader environment in terms of geopolitical, supply market and product factors and suggest that these factors serve as an expansive source of uncertain, complex, dynamic and interdependent cues that drive equivocality within the SDR decision-making process.

Geopolitical Factors. Geopolitical factors can generally be classified as governmental, natural and societal disruptions (Iankova and Katz 2003) and involve equivocality "arising from supply chain distance such as disruption caused by political (e.g., fuel crisis), natural (e.g., foot and mouth disease outbreak, fire, earthquake) or social (e.g., terrorist attacks) uncertainties" (Juttner 2005, p. 121). A government's formal policies, such as nationalization and confiscation mandates, exchange controls, workforce safety laws and local content requirements, and informal policies, which may tacitly allow bribery and corruption, drive uncertainty through the creation of a problematic or overly regulated exchange environment (Iankova and Katz 2003; Peck 2005). Uncertainty is exacerbated when transactions involve international exchange; in such cases, asymmetries of information render monitoring difficult and permit deception in contracting (Bhattacharyya, Datta and Offodile 2010). Further, international exchange increases the complexity of transactions as buyers must bridge disparate political, legal, monetary, logistical and cultural systems (David 2004).

Natural disasters, such as fires, floods, windstorms and earthquakes, and societal disruptions, which include excess violence, outbreak of disease, terrorist attacks, revolutions, strikes, war and protest, similarly introduce higher levels of equivocality into the SDR decisionmaking process (Berger, Gerstenfeld and Zeng 2004; Giunipero and Eltantawy 2004; Sheffi and Rice 2005). Such events may directly or indirectly affect flows of direct materials by rendering suppliers' production facilities or supporting infrastructure (e.g., roads, ports and communication systems) inoperable (Wagner and Bode 2008). Uncertainty driven by the inability to predict the onset, severity or impact of natural disasters and societal disruptions renders both a priori and ex post mitigation difficult (Altay and Ramirez 2010). Further, the relative infrequency of these exogenous events suggests that buyers accumulate limited retained understanding that may be drawn upon to resolve the equivocality that stems from these situations (Spekman 
and Davis 2004). Accordingly, extant research is rich with examples which suggest that multiplicity of perceptions and actions typify emergency situations (Weick 2001; Sheffi and Rice 2005).

Supply Factors. Whereas geopolitical factors incorporate a global view of the transactional environment, supply factors involve supplier, supply network and supply market attributes. Extant SDR research suggests that supplier factors, such as supplier performance variation and supplier proximity, introduce complexity and uncertainty into the SDR decision-making process. Inconsistent suppler performance, stemming from suppliers' inadequate product and/or product-related capabilities, materializes in the form of insufficient supply capacity, poor product quality, lack of product innovation and inability to reduce costs; such problems complicate buyers' coordination efforts (Zsidisin 2003a; Spekman and Davis 2004; Zsidisin, Ellram, Carter and Cavinato 2004). The level of uncertainty and complexity increases as buyers source direct materials with distant suppliers. Whereas proximal suppliers facilitate higher levels of buyer-supplier coordination (Kaynak 2002), coordination of distant suppliers is complicated by the increased likelihood of (i) higher transportation lead times and (ii) multimodal shipments (Peck 2005). Further, longer lead times increase the need to manage higher inventory levels and difficulty of responding to demand variation in product volume and mix (Zsidisin and Ellram 2003).

The supply network refers to the current members of a firm's upstream supply chain. Supply network attributes, such as complexity and density, may also increase the equivocality associated with the supply environment. Drawing from Choi and Krause (2006), we conceptualize supply network complexity as a multidimensional concept that includes the (i) number of suppliers, (ii) differentiation of suppliers and (iii) interrelationships among suppliers in the supply chain. The number of suppliers reflects the size of a firm's direct materials supply base; whereas too many suppliers increase the complexity of coordination and control, too few suppliers (as with thin markets) may result in overdependence and increased equivocality that stems from supplier opportunism and limited information flows. Differentiation of suppliers concerns the extent to which suppliers within a supply base do not share common culture, practices or systems. As in the case of the keiretsu, low levels of differentiation facilitate shared understanding which limits complexity; however, complexity increases as buying firms manage suppliers whose cultures and practices are more heterogeneous in nature (Choi and Krause 2006). Interrelationships are defined as supplier-supplier relationships that exist within a firm's supply base; to the extent that interrelationships facilitate the alignment of culture, practices and systems, supplier-supplier relationships mitigate the complexity inherent in a supply network
(Choi and Krause 2006). Supply network density refers to the geographic spacing of suppliers comprising the upstream supply chain (Craighead et al. 2007). A densely located supplier network, through its interaction with geopolitical factors, may have a significant effect on equivocality as a greater portion of the supply network may be simultaneously impacted by government action, natural disaster or societal disruption.

The supply market is comprised of all current and potential suppliers of a firm's direct material. Supply market attributes, such as thinness and dynamism, may also contribute to the level of equivocality that stems from the environment. Whereas thinness refers to the number of suppliers capable of supplying a direct material (Cannon and Perreault 1999), dynamism represents the fluctuation in the manufacturing capacity or price of purchased goods in the supply market (Zsidisin 2003a). In thin markets, where there are fewer suppliers, buyers are more dependent on existing suppliers; the resulting dependence increases the likelihood that suppliers will behave opportunistically (Bensaou and Anderson 1999). Further, thin markets offer buyers fewer opportunities to gain market insights from alternate suppliers (Cannon and Perreault 1999). Together, the increased likelihood of supplier opportunistic behavior and reduced information flow introduce equivocality as buyers' ability to understand the motives that underlie suppliers' actions are severely inhibited. Alternately, dynamic supply markets, characterized by rapid structural change, infuse uncertainty into the underlying value proposition of a purchased good. Such dynamism may be structural in nature; low barriers to entry and rapidly changing product technology may facilitate the rise of new entrants (Porter 1980). Conversely, supply markets characterized by mature product technologies and high levels of competition are subject to consolidation and exit of existing firms which cause the competitive landscape to change (Hallikas and Varis 2009). In a dynamic market, equivocality ensues as changes in the market outpace growth in a buyer's retained understanding of potential suppliers, available products offered by the market and the prevailing price per product feature.

Product Factors. Product attributes, such as customization and the nature of underlying technology, may also affect the level of equivocality inherent within the SDR decision-making process. Product customization refers to the extent to which the specifications of the direct materials are singular to the buying firm (Perdue and Summers 1991) and necessitates relationship-specific investments with suppliers to develop capabilities that match customers' specific needs (Stump, Athaide and Joshi 2002). Buyers' dependence on suppliers increases as suppliers' investments in specialized plants, equipment and personnel effectively reduce the number of available sources of supply (Hallen, Johanson and Seyed-Mohamed 1991). Equivocality stems from product 
customization as (i) the resulting thin markets permit suppliers' opportunistic behavior and limit information flows (Hedge, Kekre, Rajiv and Tadikamalla 2005) and (ii) the deviation from standard product designs necessitates proprietary interfaces, increasing the complexity of coordination between buyer and supplier (Novak and Eppinger 2001). The dynamism of product technology - the rate of technological change for a particular product technology in an industry (Dröge, Claycomb and Germain 2003) - also impacts the level of equivocality inherent in the supply environment (Weick 2001). Rapid technological change obfuscates performance expectations as buyers must learn the intricacies of new technologies to adequately evaluate supplier capabilities and effectively resolve supply chain issues. With rapidly changing technologies, standards for price and value assessments become ambiguous as retained understanding lags technological advancement (Ellis et al. 2010).

Equivocality. In aggregate, we assert that uncertainty, complexity, dynamism and interdependence represent overlapping properties of the supply environment that affect the level of equivocality of the SDR decisionmaking process. Whereas uncertainty raises the prospect for equivocality due to "a lack of information about cause-effect relationships" (Milliken 1987, p. 134), complexity, which captures "the number of elements within the system and the degree to which these elements are differentiated" (Choi and Krause 2006, p. 5), increases the likelihood that a buyer will confront the unknown. In the same vein, dynamism suggests that an individuals' extant knowledge, conceptualized as retained understanding, may not keep pace with the rapidly changing environment (Achrol and Stern 1988). Further, interdependence requires close interlocking behaviors, which impose complexities of coordination (Weick 2001). Through these mechanisms, we suggest that geopolitical, supply and product attributes associated with the supply environment impose difficulty in establishing a singular meaning that informs decision-making.

Proposition 1: The level of uncertainty, complexity, dynamism and interdependence associated with geopolitical, supply market and product factors is positively associated with the level of equivocality inherent in the SDR decision-making process.

\section{Organization}

The predominant view in the sense-making literature is that organizations are an "internal cognitive constraint" (Barley and Tolbert 1997) or "structures that constrain sense-making by making some actions unimaginable and others self-evident" (Weber and Glynn 2006, p. 1641). Organizing serves to reduce the level of equivocality from the environment by "[shaping] what people say and do, [shaping] what people notice in their deeds and dis- course, and [shaping] the thoughts, presumptions, and labels that people treat as their beliefs" (Weick 2001, p. 96). Previous supply risk research suggests that two general sets of organizational factors may play an important role in the management of supply disruptions: (i) systems and structures and (ii) controls (Mitchell 1995). We propose that these sets of organizational factors serve to reduce equivocality through policies, procedures, information and social interactions that affect an individual's sense-making process. Organizational structures, systems and controls influence what buyers pay attention to and what justifications of the enacted environment are considered appropriate. Through their effect on the sense-making process, organizational factors facilitate buyers' capacity to cope with equivocality inherent in SDR decisions.

Organizational Structure and Systems. Organizational structure and systems act to reduce environmental equivocality by facilitating sensible interpretation (i.e., selection) and group mind (i.e., retention). Weick (2001) identifies several aspects of organizational structure that are germane to the sense-making process: level of decentralization, composition of work teams and staffing level. Decentralization refers to the extent to which authority for decision-making is distributed throughout lower levels of the organization (Lee and Choi 2003). Relative to centralization, decentralized structure facilitates understanding as (i) actions are not impeded by vertical communication flows and requests for approval and (ii) authority to act resides with those most knowledgeable to act. Accordingly, decentralization promotes more frequent enactment and subsequent interpretations that make sense of previous actions while leading to appropriate future actions (Weick 2001). Composition of work teams reflects the nature and distribution of knowledge and underlying experience of those who collaborate to accomplish organizational goals. Both breadth of knowledge and knowledge overlaps facilitate development of comprehensive group mind (Weick 2001). Whereas breadth of knowledge increases the likelihood of the team's familiarity with current circumstances, knowledge overlaps provide the mutual understanding that enables group mind (Weick, Sutcliffe and Obstfeld 2005). As such, teams having broad, overlapping knowledge and experiences may leverage a richer group understanding to resolve equivocality. In a similar vein, understaffing limits the capacity to cope with equivocality as the number of individuals available to act, interpret and form group mind is reduced (Weick 2001).

Organizational information systems provide additional means to cope with equivocality that stems from the environment (Mitchell 1995; Zsidisin et al. 2004). Rich information systems, and their related technologies, facilitate the collection, storage and processing of information that enables the 
characterization of the supply environment through (i) analytical and decision support, (ii) identification and presentation of environmental cues, (iii) support of group mind, (iv) information presentation and (v) timely feedback. Whereas transaction systems facilitate the assessment of historical data, decision support tools permit further understanding of the environment through simulation and what-if analyses (Murphy and Wood 2004). Accordingly, analytical and decision support tools augment retained understanding and facilitate sensible interpretation of prior actions. Information systems also affect the specific cues to which individuals attend. Given the infinite number of ways in which continuous experience may be parsed, information systems can identify and present salient cues that support meaningful interpretation and effective action while dismissing those cues that are superfluous (Craighead et al. 2007). Further, information sharing facilitates the development of group mind; through information sharing, relevant pieces of related experience can be pooled across multiple members of the organization such that integrated organizational understanding is enhanced. In addition, information systems influence how information is represented to actors; data format, presentation and context influence both preference and judgment (Tversky and Kahneman 1981; Stone, Yates and Parker 1994). Thus, through data representation, information systems reduce equivocality by constraining (i) preference that guides enactment and (ii) interpretation that influences judgment of prior actions. Finally, information systems promote equivocality reduction by facilitating timely transmission and receipt of messages. Timely feedback enables prompt revisions to interpretation and swift updates to retained understanding that enable further sense-making efforts (Weick 2001).

Organizations may further increase the capacity to resolve equivocality through the use of risk assessment systems that formalize scanning and information processing efforts (Lewis 2003). Scanning refers to the breadth and depth to which the external environment is examined for salient cues; alternately, information processing reflects the translation of cues into meaningful information that promotes shared understanding (Weick 2001). Together, scanning and information processing reduce equivocality by advancing organizational knowledge (Brown, Stacey and Nandhakumar 2007). In general, formal risk assessment systems use a four-step process in which (i) top management approves resources to support the risk management process, (ii) vulnerable key processes, assets, facilities and human populations are identified, (iii) specific vulnerabilities, probabilities of occurrence and risk reducing activities are evaluated and (iv) an ongoing reporting and auditing team is implemented (Kleindorfer and Saad 2005). The output from this process may enhance organizational understanding such that a comprehensive representation of the supply environment is shared within the organization.

Proposition 2: Decentralized structure, diverse work teams with overlapping knowledge, staffing level and systems that enable rich information flows and formal assessment are negatively associated with the level of equivocality inherent in the SDR decision-making process.

Organizational Controls. Organizational controls, such as rules, roles, reward systems and culture, represent social mechanisms that facilitate interpretation of the environment and shape behavior. Identity and identification are central components of sense-making (Weber and Glynn 2006). Weick et al. (2005, p. 416) assert, "who we think we are (identity) as organizational actors shapes what we enact and how we interpret." One element of identity construction can be found in the roles that are established for organizational actors. Roles emerge from justifications of committed action and reflect a "set of both expected and enacted behaviors" that facilitate heedful interaction among members of an organization (Zigurs and Kozar 1994, p. 277). As such, roles reduce equivocality by guiding enactment and defining appropriate types of response. Whereas roles generally describe duties associated with a particular position, rules reflect general policy and preset responses to standardized situations (Scott 2001). The capacity of the organization to cope with equivocality increases as (i) the "severity, number, latitude for deviations and clarity" of rules intensifies, (ii) agreement on "the content of rules, the nature of violations and how violations will be handled" increases and (iii) the speed with which "people learn about the effects of their actions" increases (Weick 2001, p. 43). Thus, roles and rules affect organizational capacity to cope with equivocality by defining appropriate action and aiding recognition and interpretation of cause-effect relationships.

Rewards systems reinforce the alignment between employees' actual and expected behavior through three mechanisms: (i) performance definition, (ii) performance appraisal and (iii) performance feedback (Summers 2005; Noe, Hollenbeck, Gerhart and Wright 2008). Through performance definition, employee goals that are congruent with those of the organization are identified and set (Folan and Browne 2005). Whereas appraisal involves the assessment of employee performance, feedback facilitates adjustment in employee behavior. Thus, reward systems, when linked to employee performance, affect enactment by motivating desired organizational behaviors (Rynes, Gerhart and Parks 2005; Ritchie and Brindley 2007b). In addition, behavior-based reward systems may promote organizational learning by (i) rewarding nonevents (i.e., the 
absence of crisis), enactment and communal behaviors and (ii) permitting failure (Weick 2001; Zsidisin and Ellram 2003); by facilitating an organizational environment that promotes learning, the capacity to reduce equivocality is increased.

Culture refers to the enduring beliefs of an organization (Scott 1998) and is embodied within organizational values, paradigms and stories (Bruner 1991). Organizational values represent social agreement on the criteria that distinguishes acceptable action, sensible interpretation and effective performance (Oyserman 2002). Organizational values reside in group mind and guide heedful, coordinated action by affecting preferences for action and providing capacity for judgment (Weick 2001). Further, values enhance organizational sense-making by driving the need to explain behavior to one's important peers in a socially acceptable manner (Weick 2001). In a similar vein, organizational paradigms are dominant beliefs about underlying patterns or models and arise from strong socially accepted justifications (Isabella 1990). A dominant model within an organization "improves prediction, [and] allows a higher level of agreement on cause-effect relationships and/or preferences" (Weick 2001, p. 80); in this way, paradigms facilitate equivocality reduction. Stories provide means to propagate values and paradigms throughout the organization; stories are particularly useful supplements to experience when trial and error is not possible (Bruner 1991). As an equivocality coping tool, shared stories "provide general guidelines within which they [individuals] customize diagnoses and solutions to local problems" (Weick 2001, p. 341). In sum, because rules, roles and reward systems rely on precedence for effect, culture represents a particularly powerful means to reduce equivocality.

Proposition 3: Organizational controls, such as roles, rules, rewards systems and culture, are negatively associated with the level of equivocality inherent in the SDR decision-making process.

\section{Individual}

Within the context of SDR, we suggest that the sensemaking process serves as the basis for the SDR decisionmaking process in which the adoption of risk mitigation tactics, judgments and evaluations of SDR, and understanding of the supply market are closely linked. Although these linkages exist within an individual's mind, the activities associated with the underlying sense-making process are both psychological and social in nature.

SDR Decision-Marking as Sense-Making Process. In highly equivocal situations, the sense-making process begins with enactment. Faced with multiple potential interpretations of environment, "people often don't know what the 'appropriate action' is until they take some action and see what happens" (Weick 2001, p. 225). Enactment involves actions that provide the stream of episodes that may be singled out for subsequent interpretation. During enactment, preconceptions guide actions aimed at managing a situation; through such actions, equivocality - the raw material of sense-making - is introduced into the sense-making process (Weick 1969). Equivocality is reduced through (i) subsequent stages of the sense-making process and (ii) later enactments, which incorporate feedback from previous enactments and simplify problem structure (Weick 2001). Thus, through action, individuals both determine and affect the situation and develop knowledge of a previously equivocal environment; in this way, an enacted environment is created.

In the context of SDR, buyers enact risk mitigation practices under the preconception of effectively shaping the supply environment. Several risk mitigation practices, such as early supplier involvement, logistics integration and supplier development, rely on extensive joint buyersupplier efforts to eliminate disruptions caused by poor product quality, late delivery and excessive costs (WatersFuller 1995; Krause, Scannell and Calantone 2000; Giunipero and Eltantawy 2004; Zsidisin and Smith 2005). Early supplier involvement is a collaborative activity in which buyers involve suppliers in the initial stages of the product development cycle (Zsidisin and Smith 2005). Through early involvement in buyers' product development processes, suppliers may leverage internal expertize to influence buyers' product designs (Primo and Admundson 2002). Supplier involvement requires extensive bilateral sharing of proprietary information and joint problem solving, which is often facilitated by the colocation of supplier personnel at buyers' design centers (Clark and Fujimoto 1991). Similarly, logistics integration refers to buyer and supplier efforts to coordinate the flows of goods, services and related information throughout the supply chain (Lambert, Cooper and Pagh 1998). Extant research has identified two facilitators of logistics integration: buyer-supplier information sharing and colocation (Handfield 1993). In the same vein, supplier development involves buyers' direct investment in the improvement of current or potential suppliers' performance or capabilities (Krause 1999). Through supplier development efforts, supplier improvement is achieved through buyer's provisions of on-site technical assistance, training and investment in plant and equipment (Krause 1999). In general, early suppler involvement, logistics integration and supplier development activities aim to mitigate SDR through extensive buyer-supplier joint efforts.

Similarly, comprehensive supplier selection and formal ongoing evaluation activities advance a buyer's understanding of the supply environment by fostering supplier interactions before and following the sourcing decision, respectively. Supplier selection is a multistaged 
process in which buyers (i) identify a pool of potential suppliers, (ii) develop a short-list of acceptable suppliers and (iii) award business to suppliers that offer superior value propositions (Fawcett, Ellram and Ogden 2006). The use of comprehensive selection criteria and rigorous selection methodology facilitates the identification of suppliers that best support the firm's value creation process. Accordingly, comprehensive selection processes use (i) inclusive sets of concrete performance and behavioral selection criteria (Kannan and Tan 2002), (ii) cross-functional teams to develop selection criteria and evaluate suppliers against the selection criteria (Fawcett et al. 2006) and (iii) extensive primary and secondary data obtained through supplier selfassessment, historical databases, audits, interviews and direct observation (Talluri, Narasimhan and Nair 2006). Formal supplier evaluation involves continued periodic broad-based monitoring of suppliers following selection and the timely communication of performance feedback to suppliers (Krause et al. 2000). Thus, comprehensive supplier selection and formal evaluation resolve equivocality through significant interfunctional and interorganization joint efforts.

In contrast, contingency planning involves activities that are executed with little buyer-supplier interaction. In general, contingency planning activities involve securing excess supply capacity or holding inventory at key positions within the supply chain (Giunipero and Eltantawy 2004; Tomlin 2006). Firms may secure excess capacity using several approaches: (i) contracting with multiple suppliers, (ii) contracting with suppliers with low capacity utilization or with suppliers that maintain redundant manufacturing systems that are globally distributed (Lewis 2003) or (iii) investing in in-house manufacturing capacity (Chopra and Sodhi 2004; Tomlin 2006). Alternately, contingency plans may direct firms to hold raw material, work-in-process or finished goods inventory to mitigate the effects of a supply disruption (Zsidisin and Ellram 2003; Giunipero and Eltantawy 2004).

SDR mitigation practices, therefore, vary in terms of their focus, level of buyers' and suppliers' involvement, and subsequently, the extent of inherent committed action. Drawing from enactment theory, we suggest that the degree to which the adoption of a particular mitigation approach facilitates sense-making is contingent upon the level of commitment inherent in the risk mitigation practice. Committed action plays an important role in conceptually linking SDR mitigation enactments and richer understanding of the supply environment. In particular, SDR mitigation actions characterized by higher levels of organizational visibility and investment are more difficult to undo or disown. Such conditions bind individuals to their actions, increase the tenacity of socially acceptable justification, and, as with self-fulfilling prophecies, motivate future enactments that validate the initial justification and desired ends (Weick et al. 2005). Thus, each interaction in the series of related enactments provides additional opportunities for sensemaking, which serves to further reduce equivocality, bolster retained understanding and facilitate the development of a richer enacted environment.

Proposition 4: Buyer's use of risk mitigation tactics that invoke higher levels of committed action is negatively associated with the level of equivocality inherent in the SDR decision-making process.

Selection and retention are the underlying activities that enable the formation and storage of judgments and evaluations of SDR. Judgment refers to the "the appraisal and choice of values, intrinsic goods, and ends" and involves making comparisons (Weick 2001, p. 363). Similarly, as conceptualized by Yates and Stone (1992), judgment and evaluation activities force meaning upon situation. In particular, Yates and Stone (1992) assert that judgments of risky situations materialize in the form of perceptions of loss, loss significance and loss likelihood. Accordingly, judgments represent the synthesis of feedback from prior enactment, changes in context and retained understanding. Through cognitive processes, judgments of loss are aggregated to form the basis for an overall evaluation of risk (Yates and Stone 1992). In the context of SDR decision-making, equivocal supply situations are processed by buyers as they (i) enact SDR mitigation actions, (ii) integrate feedback with retained understanding to form and refine judgments and evaluations of SDR and (iii) advance their retained understanding of the supply environment as cognitive cause maps are updated.

Our view of SDR decision-making as sense-making departs from prior behavioral models. Most notably, Yates and Stone (1992) articulate a four-stage sequential process in which situation affects judgments of loss, which influence overall evaluations of risk, which drive risk mitigation action. In contrast, we posit a process of risky decision-making that consists of similar activities, but processed by the individual in modified order. Further, we suggest that this apparent incongruence is attributable to the moderating role of equivocality. Situations characterized by little equivocality are measurable, determinant, logical and analyzable whereby the relationship between cause and effect is more easily defined (Weick 2001). Such situations diminish the role of action as a means of understanding and are conducive to the rational decision-making process in which risk assessment strategies refine retained understanding to guide SDR mitigation actions. However, equivocal environments are unanalyzable; the absence of meanings renders judgments and evaluations difficult. When faced with equivocality, individuals must take action to develop a reasonable representation of the external environment that makes sense of previous actions and suggests future 
actions. As such, the order of activities that comprise the risky decision-making process is a function of the level of equivocality inherent within the environment.

Proposition 5: The level of equivocality moderates the order of activities that comprise the SDR decisionmaking process. Under conditions of high equivocality, adoption of risk mitigation tactics precedes formation of risk judgments and evaluations, which precedes retained understanding of the supply environment. Under conditions of low equivocality, formation of risk judgments and evaluations refine retained understanding of the supply environment, which precedes adoption of risk mitigation tactics.

Individual Attributes. Individual attributes, such as personality, values, experience and cognitive abilities, affect how buyers engage and cope with equivocality. According to Weick (2001), personality traits, which include confidence in skill, disposition toward communion and emotion, play a significant role in guiding enactment within an equivocal situation. Confidence in skill is the belief that actions will be deemed effective per the criteria set forth by the organization and is borne by the presumption of logic, which motivates individuals to act more forcefully in order to validate initial presumptions (Mitchell 1995). Similar to a self-fulfilling prophesy, forceful action imposes order onto the situation, facilitating interpretations that confirm initial presumptions (Weick et al. 2005). Further, through persistent action, confident individuals resolve equivocality by enacting their view of the environment onto others. Disposition toward communion refers to an individual's innate preference for social versus independent action "and is about tolerance, trust, and non-contractual cooperation" (Weick 2001, p. 213). As the preference for communal behavior increases, individuals become more tolerant of and receptive to new ideas and experiences; accordingly, incidences of learning, which enable the development of a richer enacted environment, concomitantly increase (Weick 2001). In addition, a preference for communion enables the development of group mind, which leverages a broader shared understanding to further process equivocality (Taylor and van Every 2000). Emotion represents a feeling that follows a salient stimulus and precedes response (Berscheid, Gangestad and Kulakowski 1984). Intense negative emotions, such as threat or fear, narrow attention; thus, a propensity for intense emotional negative response limits an individual's capacity to reduce equivocality.

At the individual level, values refer to the "internalized social representations or moral beliefs that people appeal to as the ultimate rationale for their actions" (Oyserman 2002, p. 16151). Values differentiate good from bad, natural from unnatural and truth from falsity, and facilitate the alignment of goals of the individual with those of the organization (Oyserman 2002). Like personality, values provide a guide for enactment and the assumptions that drive interpretation (Weick 2001); as such, strong values facilitate equivocality reduction.

Cognitive ability and experience represent integrated attributes that affect individuals' capacity to process equivocality (Giunipero and Eltantawy 2004). Cognitive ability refers to the capacity to retrospectively draw from a wide range of resources and represents a maximum bound for retained understanding (Weick 2001). The capacity to link constructs with meaningful patterns and store both constructs and their associations in memory underlies cognitive ability (Porac et al. 1989). Whereas cognitive ability represents potential, knowledge gained through prior experience enables individuals to cope with equivocality. Further, individuals are more likely to act when they have the cognitive capacity and knowledge to effectively respond; this, in turn, heightens the accuracy of perceptions and motivates individuals to "pay attention to a wider variety of inputs because, whatever they see, they will have some way to cope with it" (Weick 2001, p. 230). Accordingly, cognitive ability and breadth of experience interact to provide the base knowledge that is available to support broader enactment and equivocality resolution.

Proposition 6: Individual attributes, such as confidence in skill, disposition toward communion, values, experience and cognitive abilities, are negatively associated with the level of equivocality inherent in the SDR decision-making process. Alternately, intensity of negative emotional response is positively associated with the level of equivocality inherent in the SDR decision-making process.

As individuals enact and interpret their actions, new knowledge of the environment is retained. Thus, buyers who (i) possess the aforementioned individual attributes and (ii) act within organizations having the aforementioned structure, systems and controls that facilitate equivocality reduction are more likely to possess greater knowledge in the form of a more comprehensive, richer mental representation of the supply environment. Further, learning is self-reinforcing; gains in knowledge facilitate sensible enactment and meaningful interpretation that further improve the capacity to retain new understanding. Because retained understanding provides the platform for subsequent enactment and selection, the efficacy of SDR mitigation tactics and accuracy of SDR judgment and evaluation is directly related to the capacity to resolve equivocality through the sense-making process. Our assertion facilitates a richer interpretation of the opening vignette whereby we suggest that Nokia Corp., through its extensive joint efforts with Philips NV, resolved considerably more equivocality than did Ericsson LM. Accordingly, Nokia Corp. enacted a more comprehensive and accurate 
representation of the supply environment that accounts for the relative effectiveness of their mitigation actions.

Proposition 7: Equivocality reduction is positively associated with the efficacy of risk mitigation tactics and accuracy of risk judgments and evaluations.

\section{DISCUSSION}

We draw from enactment theory to develop a conceptual framework that meaningfully integrates extant SDR research. Through our framework, we suggest that the sense-making process underlies SDR decision-making and provides the theoretical underpinnings that logically link the environment, organization and individual. Further, through our application of enactment theory, we introduce the central role that equivocality and its resolution play within the SDR decision-making process. In aggregate, the development of the psychological and sociological mechanisms drawn from enactment theory facilitates a richer understanding of the nomological network that integrates novel organizational and individual constructs with those previously considered within the SDR literature. The resulting conceptual framework advances new insights into the importance of perceptual views of risk, the risky decision-making process and managerial practice.

\section{Perceptual Views of Risk}

In accordance with a behavioral view of risk, our study reinforces the importance of conceptualizing risk as a perceptual rather than objective phenomenon. Consistent with an influential stream of previous research (March and Shapira 1987; Sitkin and Pablo 1992; Yates and Stone 1992), we suggest that risky decision-making is an idiosyncratically satisfying rather than rationally optimizing activity. This salient point is borne within our conceptual framework whereby we differentiate "environment" from "enacted environment." Whereas environment is consistent with a rational, objective view (e.g., Khan and Burnes 2007) that exists independent of the individual and organization, enacted environment refers to an idiosyncratic, perceptual view (i.e., mental model) that is developed and revised through the sense-making process (Weick 2001). The idiosyncratic nature of the sense-making process reaffirms previous assertions that substantive differences may exist (i) between an individual's perceptions and the objective reality of the broader environment (Boyd, Dess and Rasheed 1993) and (ii) across individuals' perceptions of the broader environment (Yates and Stone 1992). Accordingly, our use of enactment theory further substantiates the importance of understanding perceptual views of SDR. More importantly, enactment logic provides an overarching theoretical rationale that lends new insights into how perceptual biases of risk are formed.

\section{Risky Decision-Making}

With respect to the broader risky decision-making literature, our substantive theory lends new insights into the nature of the relationship between risk perception and behavior. At first glance, the SDR decision-making as sense-making process appears to conflict with dominant risky decision-making models proposed in extant research. Whereas previous studies (e.g., Sitkin and Pablo 1992; Yates and Stone 1992) explicitly assert that perceptions of risk drive behaviors or actions, enactment theory suggests that behaviors drive risk perceptions. This apparent conflict in directionality is resolved by suggesting that the incipient stage of the sense-making process is a function of the level of equivocality inherent in a situation. For situations characterized by low levels of equivocality, whereby individuals can readily relate an event to a meaningful underlying pattern, sense-making may begin with the selection process; as such, judgments and evaluations of SDR are formed, retained memory is updated and risk mitigation tactics are enacted. This is consistent with the traditional view whereby perceptions of risk precede action. However, in situations characterized by high levels of equivocality (as is the focus of Weick's enactment theory), enactment precedes understanding; that is, in equivocal situations, buyers advance their understanding of SDR through their adoption of risk mitigation tactics. Much like the doctor who makes a diagnosis through the application of treatment, buyers have little comprehension of the SDR inherent in a highly equivocal supply situation until mitigation policies are enacted.

Our adoption of enactment theory also allows us to build upon previous seminal work that studies how social influence affects risky behavior. Within their conceptual model, Sitkin and Pablo (1992) conceptualize social influence in terms of organizational culture and role model behavior. Through the lens of enactment theory, we advance the notion that social interaction is critical to sense-making and, subsequently, the risky decision-making process. In particular, we assert that social mechanisms, such as committed action and the development of group mind, significantly influence the formation of buyers' risk perceptions and behaviors. Committed action drives the need to justify enactment in a manner deemed acceptable by the focal social structure; similarly, group mind refers to the extent to which cognitive cause maps are shared across individuals within the same social structure (Weick 2001). Significant overlap of cognitive cause maps suggests that individuals share similar goals and values and indicates the prevalence of a shared organizational culture (Weick 2001). Consistent with Sitkin and Pablo's (1992) conceptual development, these social mechanisms (e.g., group mind and committed action) reinforce the assertion that culture and role model behavior influence risky decisionmaking. However, enactment theory suggests that the 
theoretical underpinnings for this assertion are attributable to the extent to which individuals are compelled to justify their enactments to other individuals in the same social structure who, by virtue of overlapping cognitive cause maps, share the same values and goals.

Similarly, our conceptual framework lends further insight into the relationship between problem domain familiarity and risky decision-making. Sitkin and Pablo (1992, p. 22) define problem domain familiarity as "the familiarity that results from increased levels of past experience in a given problem domain." In our conceptual framework, we explicitly link experience with the sensemaking process and suggest that experiences enable individuals to develop richer cognitive cause maps. However, we draw from enactment theory to suggest that the diversity of an individual's experience, in addition to the number of experiences within a focal problem domain, facilitate sense-making. A broader range of experiences, which facilitate varied capabilities and diverse logics, provides additional guidance to an individual's interpretation process (Weick 2001). Thus, as with the bricoleur - a creator of solutions that use only those resources at hand, buyers that maintain both breadth and depth of knowledge are likely to successfully cope with the SDR inherent in an equivocal situation.

\section{Managerial Implications}

Our conceptual framework and associated theoretical development also contribute to managerial practice in several important ways. Our developed theory suggests that it is important for purchasing organizations to recognize transactions that are characterized by high levels of equivocality. For such cases, situational understanding may be enhanced by tasking buyers who have significant and broad experience in purchasing with these transactions. Further, organizational structure and systems may augment buyers' equivocality reduction processes by promoting accurate views of environment and steering committed action in the desired direction. Accordingly, organizations should (i) facilitate cross-functional interaction, (ii) provide data that supports interpretational clarity and (iii) implement risk assessment systems that prompt buyers to make sense of the known and probe the unknown. Similarly, organizational systems should (i) promote the breadth and depth of buyers' knowledge through training, cross-training and job rotation, (ii) support simulation and what-if analyses to increase breadth of knowledge, (iii) ensure that roles, goals, and culture constrain buyer behavior such that total life cycle costs associated with purchases are minimized and (iv) use measurement and reward systems that provide incentives for buyers to interact with suppliers and crossfunctional colleagues to effectively manage equivocality. More broadly, our study suggests the importance of maintaining a professional social structure that extends beyond the firm's boundaries. Interaction with external purchasing professionals, through purchasing-centric organizations or trade groups, may help buyers (i) perceive a situation in a manner that is more congruent with an objective reality and (ii) establish a richer social structure that may be drawn upon when faced with conditions beyond comprehension.

\section{REFERENCES}

Achrol, R.S. and L.W. Stern. "Environmental Determinants of Decision-Making Uncertainty in Marketing Channels," Journal of Marketing Research, (25:1), 1988, pp. 36-50.

Altay, N. and R. Ramirez. "Impact of Disasters on Firms in Different Sectors: Implications for Supply Chains," Journal of Supply Chain Management, (46:4), 2010, pp. 59-80.

Babich, V., A. Burnetas and P. Ritchken. "Competition and Diversification Effects in Supply Chains with Supplier Default Risk," Manufacturing and Service Operations Management, (9:2), 2007, pp. 123-146.

Barley, S.R. and P.S. Tolbert. "Institutionalization and Structuration: Studying the Links Between Action and Institution," Organization Studies, (18:1), 1997, pp. 93-117.

Bensaou, M. and E. Anderson. “Buyer-Supplier Relations in Industrial Markets: When Do Buyers Risk Making Idiosyncratic Investments?", Organizational Science, (10:4), 1999, pp. 460-481.

Berger, P.D., A. Gerstenfeld and A.Z. Zeng. "How Many Suppliers Are Best? A Decision Analysis Approach," Omega, (32), 2004, pp. 9-15.

Berscheid, E., S.W. Gangestad and D. Kulakowski. "Emotion in Close Relationships: Implications for Relationship Counseling." In S.D. Brown and R.W. Lent (Eds.), Handbook of Counseling Psychology, Wiley, New York, NY, 1984, pp. 435-476.

Bhattacharyya, K., P. Datta and O.F. Offodile. "The Contribution of Third-Party Indices in Assessing Global Operational Risks," Journal of Supply Chain Management, (46:4), 2010, pp. 25-43.

Blackhurst, J., C. Craighead, D. Elkins and R. Handfield. "An Empirically Derived Agenda of Critical Research Issues for Managing Supply-Chain Disruptions," International Journal of Production Research, (43:19), 2005, pp. 4067-4081.

Boyd, B.K., G.G. Dess and A.M.A. Rasheed. "Divergences Between Archival and Perceptual Measures of the Environment: Causes and Consequences," The Academy of Management Review, (18:2), 1993, pp. 204-226.

Braunscheidel, M. and N. Suresh. "The Organizational Antecedents of a Firm's Supply Chain Agility for Risk Mitigation and Response," Journal of Operations Management, (27:2), 2009, pp. 119-140.

Brown, A.D., P. Stacey and J. Nandhakumar. "Making Sense of Sensemaking Narratives," Human Relations, (61:8), 2007, pp. 1035-1062.

Bruner, J."The Narrative Construction of Reality," Critical Inquiry, (18), 1991, pp. 1-21. 
Burke, G., J. Carrillo and A. Vakharia. "Single Versus Multiple Supplier Sourcing Strategies," European Journal of Operational Research, (182:1), 2007, pp. 95-112.

Cachon, G. "The Allocation of Inventory Risk in a Supply Chain: Push, Pull and Advanced Purchase Discount Contracts," Management Science, (50:2), 2004, pp. 222-238.

Cannon, J.P. and W.D. Perreault. "Buyer-Seller Relationships in Business Markets," Journal of Marketing Research, (36:4), 1999, pp. 439-460.

Choi, T.Y. and D.R. Krause. "The Supply Base and Its Complexity: Implications for Transaction Cost, Risks, Responsiveness, and Innovation," Journal of Operations Management, (24:5), 2006, pp. 637-652.

Chopra, S. and S.S. Sodhi. "Managing Risk to Avoid Supply-Chain Breakdown," MIT Sloan Management Review, (46:1), 2004, pp. 53-61.

Christopher, M. and H. Lee. "Mitigating Supply Chain Risk Through Improved Confidence," International Journal of Physical Distribution and Logistics Management, (34:5), 2004, pp. 388-396.

Clark, K.B. and T. Fujimoto. Product Development Performance: Strategy, Organization, and Management in the World Auto Industry, Harvard Business School Press, Boston, MA, 1991.

Cohen, M.A., T.H. Ho, Z.J. Ren and C. Terwiesch. "Measuring Imputed Cost in the Semiconductor Equipment Supply Chain," Management Science, (49:12), 2003, pp. 1653-1670.

Craighead, C., J. Blackhurst, M. Rungtusanatham and R. Handfield. "The Severity of Supply Chain Disruptions: Design Characteristics and Mitigation Capabilities," Decision Sciences, (38:1), 2007, pp. 131-156.

Cucchiela, F. and M. Gastaldi. "Risk Management in Supply Chain: A Real Option Approach," Journal of Manufacturing Technology Management, (17:6), 2006, pp. 700-720.

Dalgleish, F. and B.J. Cooper. "Risk Management: Developing a Framework for a Water Authority," Management of Environmental Quality: An International Journal, (16:3), 2005, pp. 235-249.

David, P.A. International Logistics, Atomic Dog Publishing, Cincinnati, OH, 2004.

Dröge, C., C. Claycomb and R. Germain. "Does Knowledge Mediate the Effect of Context on Performance? Some Initial Evidence," Decision Sciences, (34:3), 2003, pp. 541-568.

Ellis, S.C., R.M. Henry and J. Shockley."Buyer Perceptions of Supply Disruption Risk: A Behavioral View and Empirical Assessment," Journal of Operations Management, (21:1), 2010, pp. 34-46.

Faisal, M.N., D.K. Banwet and R. Shankar. "Supply Chain Risk Mitigation: Modeling the Enablers," Business Process Management Journal, (12:4), 2006, pp. 535552.

Fawcett, S.E., L.M. Ellram and J.A. Ogden. Supply Chain Management: From Vision to Implementation, Pearson Prentice Hall, Upper Saddle River, NJ, 2006.
Folan, P. and J. Browne. "A Review of Performance Measurement: Towards Performance Management," Computers in Industry, (56), 2005, pp. 663-680.

Gaudenzi, B. and A. Borghesi. "Managing Risks in the Supply Chain Using the AHP Method," The International Journal of Logistics Management, (17:1), 2006, pp. 114-136.

Giunipero, L.C. and R.A. Eltantawy. "Securing the Upstream Supply Chain: A Risk Management Approach," International Journal of Physical Distribution and Logistics Management, (34:9), 2004, pp. 698-713.

Gupta, D. "The $(\mathrm{Q}, \mathrm{r})$ Inventory System with an Unreliable Supplier," INFOR, (34:2), 1996, pp. 59-76.

Haksoz, C. and A. Kadam. "Supply Risk in Fragile Contracts," MIT Sloan Management Review, (49:2), 2008, pp. 7-8.

Hallen, L., J. Johanson and N. Seyed-Mohamed. "InterFirm Adaptation in Business Relationships," Journal of Marketing, (55:2), 1991, pp. 29-37.

Hallikas, J., K. Puumulainen, T. Vesterinen and V.-M. Virolainen. "Risk-Based Classification of Supplier Relationships," Journal of Purchasing and Supply Management, (11:2-3), 2005, pp. 72-82.

Hallikas, J. and J. Varis. "Risk Management in Value Networks." In G. Zsidisin and R. Ritchie (Eds.), Supply Chain Risk: A Handbook of Assessment, Management and Performance, Springer, New York, NY, 2009, pp. 35-52.

Hallikas, J., V.-M. Virolainen and M. Tuominen. "Risk Analysis and Assessment in Network Environments: A Dyadic Case Study," International Journal of Production Economics, (78:1), 2002, pp. 45-55.

Handfield, R.B. "A Resource Dependence Perspective of Just-in-Time Purchasing," Journal of Operations Management, (11:3), 1993, pp. 289-311.

Harland, C., R. Brenchley and H. Walker. "Risk in Supply Networks," Journal of Purchasing and Supply Management, (9:2), 2003, pp. 51-62.

Hedge, V.G., S. Kekre, S. Rajiv and P.R. Tadikamalla. "Customization: Impact on Product and Process Performance," Production and Operations Management, (14:4), 2005, pp. 388-399.

Hendricks, K.B. and V.R. Singhal. "The Effect of Supply Chain Glitches on Shareholder Wealth," Journal of Operations Management, (21:5), 2003, pp. 501-522.

Hendricks, K.B. and V.R. Singhal. "Supply Chain Glitches and Operating Performance," Management Science, (51:5), 2005a, pp. 695-711.

Hendricks, K.B. and V.R. Singhal. "An Empirical Analysis of the Effect of Supply Chain Disruptions on LongRun Stock Price Performance and Equity Risk of the Firm," Production and Operations Management, (14:1), 2005b, pp. 35-52.

Hendricks, K.B., V.R. Singhal and R. Zhang. "The Effect of Operational Slack, Diversification, and Vertical Relatedness on the Stock Market Reaction to Supply Chain Disruptions," Journal of Operations Management, (27:3), 2009, pp. 233-246. 
Ho, C.-F. "A Contingency Theoretical Model of Manufacturing Strategy," International Journal of Operations and Production Management, (16:5), 1996, pp. 74-98.

Hult, G.T.M., C.W. Craighead and D.J. Ketchen Jr. "Risk Uncertainty and Supply Chain Decisions: A Real Options Perspective," Decision Sciences, (41:3), 2010, pp. 435-451.

Iankova, E. and J. Katz. "Strategies for Political Risk Mediation by International Firms in Transition Economies: The Case of Bulgaria," Journal of World Business, (38), 2003, pp. 182-203.

Isabella, L.A. "Evolving Interpretations as Change Unfolds: How Managers Construe Key Organizational Events," The Academy of Management Journal, (33:1), 1990, pp. 7-41.

Juttner, U. "Supply Chain Risk Management: Understanding the Business Requirements from a Practitioner Perspective," The International Journal of Logistics Management, (16:1), 2005, pp. 120-141.

Juttner, U., H. Peck and M. Christopher. "Supply Chain Risk Management: Outlining an Agenda for Future Research," International Journal of Logistics: Research and Applications, (6:4), 2003, pp. 197-210.

Kannan, V.R. and K.C. Tan. "Supplier Selection and Assessment: Their Impact on Business Performance," Journal of Supply Chain Management, (38:4), 2002, pp. 11-21.

Kaynak, H. "The Relationship Between Just-In-Time Purchasing Techniques and Firm Performance," IEEE Transactions on Engineering Management, (48), 2002, pp. 205-218.

Khan, O. and B. Burnes. "Risk and Supply Chain Management: Creating a Research Agenda," The International Journal of Logistics Management, (18:2), 2007, pp. 197-216.

Khan, O., M. Christopher and B. Burnes. "The Impact of Product Design on Supply Chain Risk: A Case Study," International Journal of Physical Distribution and Logistics Management, (38:5), 2008, pp. 412-432.

Kleindorfer, P.R., J.C. Belke, M.R. Elliot, K. Lee, R.A. Lowe and H. Feldman. "Accident Epidemiology and the U.S. Chemical Industry: Accident History and WorstCase Data from RMP*Info," Risk Analysis, (23:5), 2003, pp. 865-881.

Kleindorfer, P.R. and G.H. Saad. "Managing Disruption Risks in Supply Chains," Production and Operations Management, (14:1), 2005, pp. 53-68.

Knemeyer, A., W. Zinn and C. Eroglu. "Proactive Planning for Catastrophic Events in Supply Chains," Journal of Operations Management, (27:2), 2009, pp. 141-153.

Kraljic, P. "Purchasing Must Become Supply Management," Harvard Business Review, (61:5), 1983, pp. 109-117.

Krause, D.R. "The Antecedents of Buying Firms' Efforts to Improve Suppliers," Journal of Operations Management, (17:3), 1999, pp. 205-224.

Krause, D.R., T.V. Scannell and R.J. Calantone. "A Structural Analysis of the Effectiveness of Buying
Firms' Strategies to Improve Supplier Performance," Decision Sciences, (31:1), 2000, pp. 33-55.

Kull, T. and D. Closs. "The Risk of Second-Tier Supplier Failures in Serial Supply Chains: Implications for Order Policies and Distributor Autonomy," European Journal of Operational Research, (186), 2008, pp. 1158-1174.

Lambert, D.M., M. Cooper and J. Pagh. "Supply Chain Management: Implementation Issues and Research Opportunities," The International Journal of Logistics Management, (9:2), 1998, pp. 1-19.

Lee, H. "The Triple-A Supply Chain," Harvard Business Review, (82:10), 2004, pp. 102-113.

Lee, H. and B. Choi. "Knowledge Management Enablers, Processes, and Organizational Performance: An Integrative View and Empirical Examination," Journal of Management Information Systems, (20:1), 2003, pp. 179-228.

Leopoulus, V.N. and K.A. Kirytopoulus. "Risk Management: A Competitive Advantage in the Purchasing Function," Production Planning and Control, (15:7), 2004, pp. 678-687.

Lev, B. "Environmental Uncertainty Reduction by Smoothing and Buffering: An Empirical Verification," The Academy of Management Journal, (18:4), 1975, pp. 164-171.

Lewis, A.L. "Cause, Consequence, and Control: Towards a Theoretical and Practical Model of Operational Risk," Journal of Operations Management, (21:3), 2003, pp. 205-224.

Li, C.-L. and P. Kouvelis. "Flexible and Risk-Sharing Supply Contracts Under Price Uncertainty," Management Science, (45:10), 1999, pp. 1378-1398.

Li, G., Y. Lin, S. Wang and H. Yan. "Enhancing Agility by Timely Sharing of Supply Information," Supply Chain Management: An International Journal, (11:5), 2006, pp. 425-435.

Li, Q. "Risk, Risk Aversion and the Optimal Time to Produce," IIE Transactions, (39), 2007, pp. 145158.

Manuj, I. and J.T. Mentzer. "Global Supply Chain Risk Management," Journal of Business Logistics, (29:1), 2008a, pp. 133-155.

Manuj, I. and J.T. Mentzer. "Global Supply Chain Risk Management Strategies," International Journal of Physical Distribution and Logistics Management, (38:3), 2008b, pp. 192-223.

March, J.G. and Z. Shapira. "Managerial Perspectives on Risk and Risk Taking," Management Science, (33:11), 1987, pp. 1404-1418.

Meyer, R.R., S.A. Rothkopf and A. Smith. "Reliability and Inventory in a Production-Storage System," Management Science, (25:8), 1979, pp. 799-807.

Milliken, F.J."Three Types of Perceived Uncertainty About the Environment: State, Effect, and Response Uncertainty," The Academy of Management Review, (12:1), 1987, pp. 133-143.

Mitchell, V.-W. "Organizational Risk Perception and Reduction: A Literature Review," British Journal of Management, (6:2), 1995, pp. 115-133. 
Moinzadeh, K. and P. Aggarwal. "Analysis of a Production/Inventory System Subject to Random Disruptions," Management Science, (43:11), 1997, pp. 1577-1588.

Murphy, P.R. and D.F. Wood Jr. Contemporary Logistics, 8th ed., Pearson Prentice-Hall Inc., Upper Saddle River, NJ, 2004.

Narasimhan, R. and S. Talluri. "Perspectives on Risk Management in Supply Chains," Journal of Operations Management, (27:2), 2009, pp. 114-118.

Noe, R.A., J. Hollenbeck, B. Gerhart and P. Wright. Human Resource Management: Gaining a Competitive Advantage, 6th ed., McGraw-Hill, New York, NY, 2008.

Norrman, A. and U. Jansson. "Ericsson's Proactive Risk Management Approach after a Serious Sub-Supplier Accident," International Journal of Physical Distribution and Logistics Management, (34:5), 2004, pp. 434-456.

Novak, S. and S.D. Eppinger. "Sourcing by Design: Product Complexity and the Supply Chain," Management Science, (47:1), 2001, pp. 189-204.

Oyserman, D. "Values: Psychological Perspectives." In N. Smelser and P. Baltes (Eds.), International Encyclopedia of the Social \& Behavioral Sciences, Vol. 22, Elsevier Science, New York, NY, 2002, pp. 16150 16153.

Parlar, M. and D. Perry. "Analysis of a $(\mathrm{Q}, \mathrm{r}, \mathrm{T})$ Inventory Policy with Deterministic and Random Yields when Future Demand is Uncertain," European Journal of Operations Research, (84:2), 1995, pp. 431-443.

Peck, H. "Drivers of Supply Chain Vulnerability: An Integrated Framework," International Journal of Physical Distribution and Logistics Management, (35:3/4), 2005, pp. 210-232.

Peck, H. "Reconciling Supply Chain Vulnerability, Risk and Supply Chain Management," International Journal of Logistics: Research and Applications, (9:2), 2006, pp. 127-142.

Perdue, B.C. and O.J. Summers. "Purchasing Agents' Use of Negotiation Strategies," Journal of Marketing Research, (28:2), 1991, pp. 175-189.

Pettit, T.J., J. Fiksel and K.L. Croxton. "Ensuring Supply Chain Resilience: Development of a Conceptual Framework," Journal of Business Logistics, (31:1), 2010, pp. 1-21.

Porac, J.F., H. Thomas and C. Baden-Fuller. "Competitive Groups as Cognitive Communities: The Case of Scottish Knitwear Manufacturers," Journal of Management Studies, (26:4), 1989, pp. 397-416.

Porter, M.E. Competitive Strategy, Free Press, New York, NY, 1980.

PricewaterhouseCoopers. "Supply Chain Risks Threaten Shareholder Value, PricewaterhouseCoopers Report Finds," PricewaterhouseCoopers LLP Press Release, December 8, 2008.

Primo, M.A.M. and S.D. Admundson. "An Exploratory Study of the Effects of Supplier Relationships on New Product Development Outcomes," Journal of Operations Management, (20:1), 2002, pp. 33-52.
Rao, S. and T.J. Goldsby. "Supply Chain Risks: A Review and Typology," The International Journal of Logistics Management, (20:1), 2009, pp. 97-123.

Ritchie, B. and C. Brindley. "Supply Chain Risk Management and Performance: A Guiding Framework for Future Development," International Journal of Operations and Production Management, (27:3), 2007a, pp. 303-322.

Ritchie, B. and C. Brindley. "An Emergent Framework for Supply Chain Risk Management and Performance Measurement," Journal of the Operational Research Society, (58:11), 2007b, pp. 1398-1411.

Ritchie, B., C. Brindley and C. Armstrong. "Risk Assessment and Relationship Management Practical Approach to Supply Chain Risk Management," International Journal of Agile Systems and Management, (3:3-4), 2008, pp. 228-247.

Rynes, S., B. Gerhart and L. Parks. "Personnel Psychology: Performance Evaluation and Pay for Performance," Annual Review of Psychology, (56:1), 2005, pp. 571600.

Scheid-Cook, T.L. "Organizational Enactments and Conformity to Environmental Prescription," Human Relations, (45:6), 1992, pp. 537-554.

Schmitt, A.J. “Using Stochastic Supply Inventory Models to Strategically Mitigate Supply Chain Disruption Risk," Logistics Spectrum, (42:4), 2008, pp. 22-27.

Scott, W.R. Organizations: Rational, Natural, and Open Systems, 4th ed., Prentice Hall, Upper Saddle River, NJ, 1998.

Scott, W.R. Institutions and Organizations, 2nd ed., Sage, Thousand Oaks, CA, 2001.

Sheff,, Y. and J.B. Rice Jr. "A Supply Chain View of the Resilient Enterprise," MIT Sloan Management Review, (47:1), 2005, pp. 41-48.

Sinha, P.R., L.E. Whitman and D. Malzahn. "Methodology to Mitigate Supplier Risk in an Aerospace Supply Chain," Supply Chain Management: An International Journal, (9:2), 2004, pp. 154-168.

Sitkin, S.B. and A.L. Pablo. "Reconceptualizing the Determinants of Risk Behavior," The Academy of Management Review, (17:1), 1992, pp. 9-38.

Smeltzer, L.R. and S.P. Siferd. "Proactive Supply Management: The Management of Risk," International Journal of Purchasing and Materials Management, (34:1), 1998, pp. 38-45.

Spekman, R.E. and E.W. Davis. "Risky Business: Expanding the Discussion on Risk and the Extended Enterprise," International Journal of Physical Distribution and Logistics Management, (34:5), 2004, pp. 414-433.

Stone, E.R., J.F. Yates and A.M. Parker. "Risk Communication: Absolute Versus Relative Expressions of Low-Probability Risks," Organizational Behavior and Human Decision Processes, (60:3), 1994, pp. 387-408.

Stump, R.L., G.A. Athaide and A.W. Joshi. "Managing Seller-Buyer New Product Development Relationships for Customized Products: A Contingency Model Based on Transaction Cost Analysis and 
Empirical Test," Journal of Product Innovation Management, (19:3), 2002, pp. 439-454.

Summers, L. "Integrated Pay for Performance: The HighTech Marriage of Compensation Management and Performance Management," Compensation Benefits Review, (37:18), 2005, pp. 18-25.

Sutton, S.G. "Extended-Enterprise Systems' Impact on Enterprise Risk Management," Journal of Enterprise Information Management, (19:1), 2006, pp. 97-114.

Talluri, S., R. Narasimham and A. Nair. "Vendor Performance with Supply Risk: A ChanceConstrained DEA Approach," International Journal of Production Economics, (100:2), 2006, pp. 212-222.

Tang, C.S. "Robust Strategies for Mitigating Supply Chain Disruptions," International Journal of Logistics: Research and Applications, (9:1), 2006a, pp. 33-45.

Tang, C.S. "Perspectives in Supply Chain Risk Management," International Journal of Production Economics, (103:2), 2006b, pp. 451-488.

Taylor, J.R. and E.J. van Every. The Emergent Organization: Communication as Its Site and Surface, Lawrence Erlbaum Associates, Mahwah, NJ, 2000.

Tomlin, B. "On the Value of Mitigation and Contingency Strategies for Managing Supply Chain Disruption Risks," Management Science, (52:5), 2006, pp. 639657.

Tomlin, B. and Y. Wang. "On the Value of Mix Flexibility and Dual Sourcing in Unreliable Newsvendor Networks," Manufacturing and Service Operations Management, (7:1), 2005, pp. 37-57.

Treleven, M. and S.B. Schweikhart. "A Risk/Benefit Analysis of Sourcing Strategies: Single vs. Multiple Sourcing," Journal of Operations Management, (7:3-4), 1988, pp. 93-114.

Tversky, A. and D. Kahneman. "The Framing of Decisions and the Psychology of Choice," Science, (211:4481), 1981, pp. 453-458.

Wagner, S. and C. Bode. "An Empirical Investigation into Supply Chain Vulnerability," Journal of Purchasing and Supply Management, (12:3), 2006, pp. 301-312.

Wagner, S. and C. Bode. "An Empirical Examination of Supply Chain Performance Along Several Dimensions of Risk," Journal of Business Logistics, (29:1), 2008, pp. 307-325.

Waters-Fuller, N. "Just-In-Time Purchasing and Supply: A Review of the Literature," International Journal of Operations and Production Management, (15:9), 1995, pp. 220-236.

Watson, G. "Uncertainty and Contractual Hazard in the Film Industry: Managing Adversarial Collaboration with Dominant Suppliers," Supply Chain Management: An International Journal, (9:5), 2004, pp. 402-409.

Weber, K. and M.A. Glynn. "Making Sense with Institutions: Context and Action in Karl Weick's Theory," Organization Studies, (27:1), 2006, pp. 1639-1660.

Weick, K.E. The Social Psychology of Organizations, Addison-Wesley Publishing Co., Reading, MA, 1969.

Weick, K.E. Sensemaking in Organizations, Sage Publications Inc., Thousand Oaks, CA, 1995.

Weick, K.E. Making Sense of the Organization, Blackwell Publishers Inc., Malden, MA, 2001.

Weick, K.E., K.M. Sutcliffe and D. Obstfeld. "Organizing and the Process of Sensemaking," Organization Science, (16:4), 2005, pp. 409-421.

Yates, J.F. and E.R. Stone. "The Risk Construct." In J.F. Yates (Ed.), Risk-Taking Behavior, Wiley, New York, NY, 1992, pp. 1-25.

Zigurs, I. and K.A. Kozar. "An Exploratory Study of Roles in Computer-Supported Groups," MIS Quarterly, 1994, (18:3), pp. 277-297.

Zsidisin, G. and L. Ellram. "An Agency Theory Investigation of Supply Risk Management," Journal of Supply Chain Management, (39:3), 2003, pp. 15-29.

Zsidisin, G.A. "A Grounded Definition of Supply Risk," Journal of Purchasing and Supply Management, (9:5-6), 2003a, pp. 217-224.

Zsidisin, G.A. "Managerial Perceptions of Supply Risk," Journal of Supply Chain Management, (39:1), 2003b, pp. 14-25.

Zsidisin, G.A., L.M. Ellram, J.R. Carter and J.L. Cavinato. "An Analysis of Supply Risk Assessment Techniques," International Journal of Physical Distribution and Logistics Management, (34:5), 2004, pp. 397-413.

Zsidisin, G.A., S. Melnyk and G. Ragatz. "An Institutional Theory Perspective of Business Continuity Planning for Purchasing and Supply Management," International Journal of Production Research, (43:16), 2005, pp. 3401-3420.

Zsidisin, G.A., A. Panelli and R. Upton. "Purchasing Organization Involvement in Risk Assessments, Contingency Plans, and Risk Management: An Exploratory Study," Supply Chain Management: An International Journal, (5:4), 2000, pp. 187-197.

Zsidisin, G.A. and M.F. Smith. "Managing Supply Risk with Early Supplier Involvement: A Case Study and Research Propositions," Journal of Supply Chain Management, (41:4), 2005, pp. 44-57. 